\title{
Drowning in Metrics: How Managers Select and Trade-off Metrics for Making Marketing Budgetary Decisions
}

\author{
Ofer Mintz
}

Yakov Bart

Peter Lenk

David J. Reibstein

August 2019

\begin{abstract}
* Ofer Mintz (Ofer.Mintz@uts.edu.au) is Senior Lecturer and Associate Head (External Engagement) of the Marketing Department at the UTS Business School, University of Technology Sydney, Sydney, Australia 2024. Yakov Bart (y.bart@ northeastern.edu) is Associate Professor of Marketing, D’Amore-McKim School of Business, Northeastern University, Boston, Massachusetts, USA 02115. Peter Lenk (plenk@umich.edu) is Professor of Technology \& Operations and Marketing, Ross School of Business, University of Michigan, Ann Arbor, MI, USA 48109. David J. Reibstein (reibstein@wharton.upenn.edu) is the William S. Woodside Professor and Professor of Marketing, The Wharton School, University of Pennsylvania, Philadelphia, PA, USA 19010. The authors thank the Marketing Science Institute (MSI) for its generous financial support. In addition, they thank Gary Lilien, seminar participants at the University of New South Wales, and participants at Marketing Meets Wall Street, Marketing Science, and Winter AMA Conferences for valuable feedback.
\end{abstract}




\title{
Drowning in Data: How Managers make Trade-offs between Metrics when making Marketing Budgetary Decisions
}

\begin{abstract}
Despite the proliferation of big data and quantitative information available for marketing decisions, surprisingly, we know little about which metrics marketers use for their decisions or how marketers make trade-offs between such metrics. To overcome this gap, in this paper, we first propose a model based on over 200 interviews conducted and a multi-disciplinary literature review of managerial metric preferences. Second, we obtain responses from 563 managers with authority on over $\$ 1$ million marketing budgets who selected metrics to include in 1,126 idealized build-your-own (BYO) conjoint choice marketing budget dashboards, and rank-ordered these metrics for 2,252 internal to marketing and external to marketing, approval seeking decision tasks. Finally, we estimate managers' preferences by proposing a random utility model that combines the BYO choice and ranking tasks to correct for selection effects. Results of our analysis, including finding systematic differences in metric utility based on type of marketing decision and detecting substantial heterogeneity in preferences among managers, provide an understanding of contextual drivers of preferences for metrics and helps establish benchmarks based on such preferences.
\end{abstract}

Keywords: metrics; managerial decision making; menu-based conjoint analysis; dashboards; marketing budget 
The digital transformation of business over the last couple of decades has led to an unprecedentedly rich information environment for firms to better understand their customers and competitors. For marketing managers, the information-based transformation has resulted in a growing number of various metrics that they can now rely on for making their decisions (Farris et al. 2010) and an increase in pressure to exhibit accountability and justify their marketing decisions via the use of such metrics (Verhoef and Leeflang 2009). Further, the informationbased transformation has also resulted in marketing managers getting progressively more concerned about "metric overload" (e.g., See 2007) and often believing that they are "drowning in metrics" while being unsure which specific metrics to employ for their decisions (e.g., Moe 2014).

Normative theory suggests that when marketing managers are making their decisions, they should use all relevant metrics or information in their decisions to maximize their knowledge and to improve decision quality. Yet, prior research has repeatedly found that people are limited by their cognitive resources, so they cannot access all information available and instead employ heuristics to simplify their decision making (e.g., Simon 1956). Further, extensive laboratory research has found that decision makers typically do not access all possible information due to search costs and information overload (e.g., Bettman, Luce, and Payne 1998; Jacoby, Chestnut, and Fisher 1978). In the context of managerial decision making, this implies that marketing managers must make trade-offs among metrics they use for making decisions in various business contexts (Lehmann and Reibstein 2006). However, as discussed in the next section, academic research and theory has not addressed this metric trade-off issue. Hence, Moorman and Day (2016) advocate for research to understand "how metrics use influences individual marketing decision making, including the decision-making processes activated and 
trade-offs manifested when marketers use different types of metrics" (p. 20). Consequently, despite its importance to theory and practice, less is known on how managers are making such data reduction trade-offs.

To address this challenge, we propose and implement a novel empirical methodology to estimate a behavioral model of managerial preferences and related trade-offs among multiple metrics. Our focus is on how two dimensions, decision type and task, influence managerial metric preferences and trade-offs, while also accounting for various characteristics of the manager, firm, industry, data quality, and marketing function. The reason for this foci is threefold. First, for over the past decade, we have conducted more than 200 interviews with managers in regards to their metric use, ${ }^{1}$ and a key message repeatedly expressed was the information managers use to make a decision (internally) may differ from the information managers use to convince others (e.g., superiors) to get behind that decision (externally). For example, one senior manager from a Fortune 500 company mentioned that "I know what data I rely on for making my decisions, it is a different set I need to convince my CFO that we should spend the money." Thus, we expect managerial preferences for metrics to vary across the internal vs. external decision context. In the managerial accounting literature, this is classified as the role in which metrics are being employed to assist (e.g., Demski and Feltham 1976; Sprinkle 2003). Yet, this internal vs. external assistance has not been addressed previously in the marketing literature.

Second, based on prior marketing literature and value chain theory (Lehmann and Reibstein 2006), we expect metric preferences to vary based on the type of marketing budget decision being made. That is, managerial preferences for different metrics are expected to vary

\footnotetext{
${ }^{1}$ These interviews were conducted by our co-author team with executives, on Measured Thoughts on SiriusXM Radio, www.measuredthoughts.com/radio-shows, and in additional anonymized in-person, one-on-one interviews.
} 
for decisions about pricing versus other critical marketing mix decisions made by marketers such as trade promotions or traditional advertising decisions. Third, literature in data quality (e.g., Pipino, Lee, and Wang 2002) and various business disciplines (i.e., marketing, management, accounting, information systems, and economics), have identified underlying properties of the data and characteristics of the manager, firm, marketing function, and industry as potential covariates of managerial metric preferences.

Consequently, to address how managers are making trade-offs between the metrics available to them when making their marketing decisions, we investigate how preferences of metrics differ by specific marketing budget decision for internal versus external decision tasks, and explore how manager, firm, and industry settings moderate these preferences. Our empirical approach combines an innovative adaptation of conjoint analysis with an idealized design. To accomplish this, first, we ask managers to create idealized build-your-own (BYO) (Liechty, Ramaswamy, and Cohen 2001) marketing budget dashboards of metrics for two types of marketing budget decisions. Then, we ask the managers to rank-order each of these metrics included in their BYO dashboards based on their level of importance for internal and external decision tasks. Finally, we ask the managers to provide information on their firms, industries, themselves, and beliefs on the importance of several properties of data quality.

We collect data from 563 managers with decision authority of $>\$ 1$ million marketing budgets who reported metric inclusion information on 1,126 idealized BYO conjoint choice marketing budget dashboards and the rank-orders between the included metrics for 2,252 internal to marketing and external to marketing decision tasks. We build a statistical model that fuses this data into a single integrated model in order to estimate managerial metric preferences based on BYO selections and rank-order tasks, while accounting for various covariates that could also 
impact such managerial preferences. Our results on managerial preferences for (against) metrics in certain decision types and tasks, and drivers of such preferences, should improve managerial marketing decision making and provide benchmarks to build better marketing dashboards, resulting in contributions to practice and theory. For example, we find satisfaction and total customers are the two metrics managers most prefer, while Tobin's Q and consideration set are the two metrics managers least prefer. Further, we find systematic differences in metric utility based on type of marketing decision, such as net profit is more preferred for distribution decisions and less preferred for trade promotions. We also detect substantial heterogeneity in preferences among managers, where managers who are more concerned about measurement issues tend to prefer metrics that are based on accounting or financial information, such as profitability, than metrics that are based on psychometrics, such as customer preferences to the brand or product. In addition, we find that managers who include Tobin's Q in their idealized marketing budget dashboards typically rank the metric highly and those managers from better performing firms also have greater preferences for Tobin's Q, which provides considerable contrasts to the negative preferences of Tobin's Q from the average manager in the sample. By utilizing the full-set of empirical results of managerial preferences for metrics, firms, consultants, and academics can create personalized dashboards tailored to firm, industry, and manager contexts to improve managerial accountability and decision quality, as discussed in greater detail in the Discussion section.

\section{Background}

Metrics comprise of information that "quantifies a trend, dynamic, or characteristic" (Farris et al. 2010, p. 1). They are used as decision aids by managers when making their individual decisions to help consider, benchmark, and monitor such trends, dynamics, and characteristics (Mintz and 
Currim 2013). However, metrics differ in their characteristics, meanings, and limits (Srinivasan and Hanssens 2009). Thus, no "silver bullet" metric has been found that is always best for managers to employ for their decisions (Ambler and Roberts 2008). Instead, it is has been recommended that managers employ a portfolio of metrics in order to achieve superior performance (Petersen et al. 2009), but it is unknown how managers make trade-offs among the metrics they want to include for their marketing budget decisions.

This lack of knowledge is a surprise given the large number of academic studies conducted on managerial information or metric use (summarized in Table 1, which is located after the references). For example, one repeated finding is that the number of metrics managers used for their marketing decisions is much smaller than the number of available metrics. Further, previous research has identified good reasons for this discrepancy between numbers of metrics available and used: gathering such data is costly, looking at too much data is cognitively taxing, and managers have limited cognitive resources (e.g., Bettman, Luce, and Payne 1998; Simon 1956). This suggests that managers cannot consider or use all relevant information available when they make their decisions, but instead must make trade-offs between metrics (or information) to use so as not to be overwhelmed (Lehmann and Reibstein 2006). However, less is known on how such trade-offs are made.

\section{Related Literature}

The conceptual framework proposed in the next section to address this gap is guided by previous research in a bevy of domains - consumer behavior and psychology, marketing strategy and management, quantitative marketing, managerial accounting, information systems, and statistics.

In the consumer behavior and psychology fields, there is extensive laboratory research demonstrating that decision makers typically do not access all possible information due to search 
costs and information overload constraints (e.g., Jacoby, Chestnut, and Fisher 1978; Malhotra 1982). Instead, decision makers typically create consideration sets to screen information into a more manageable set of information (Hauser and Wernerfelt 1990; Roberts and Lattin 1991) and then must make trade-offs among the information they use since decisions tend to be made based on $7 \pm 2$ pieces of information (Miller 1956; Olson and Jacoby 1972). In a related stream, marketing strategy and management research on how managers use information often focuses on what causes managers to employ more (less) information in their decisions, and how the use of such of information relates to firm performance (e.g., Frösén et al. 2016; Homburg, Artz, and Wieseke 2012; Menon et al. 1999). In addition, other researchers have investigated what drives managers to employ certain types of metrics when making their marketing mix decisions (e.g., Deshpandé and Zaltman 1982, 1984; Mintz and Currim 2013; Morgan, Anderson, and Mittal 2005). However, to our knowledge, no work in these literatures has investigated how managers make trade-offs among the multiple individual metrics they employ.

In the marketing strategy and quantitative marketing literature, value chain theory (Lehmann and Reibstein 2006) suggests that because different marketing-mix decisions have divergent goals and objectives, the importance of a metric will depend on its alignment between the goal of that type of marketing-mix decision and the information provided by the metric (Mintz, Gilbride, et al. 2019). Hence, the type of marketing-mix decision (i.e., advertising, pricing, new product development, etc.) has been shown to be an important driver of metric or information use (Mintz and Currim 2013; Perkins and Rao 1990). Previous studies (e.g., Ambler 2003; Farris et al., 2010) provide normative recommendations for which metrics managers should employ for different types of marketing-mix decisions. Yet, these works do not 
empirically test a behavioral model to support these recommendations. This is something we explore.

In the managerial accounting literature, metrics are often categorized as assisting in a decision-facilitating or decision-influencing role (Demski and Feltham 1976; Sprinkle 2003). For marketers, this implies that metrics can play differing roles when they are making internal to the function decisions in comparison to when they are used to convince others in the organization to approve their marketing efforts. Related, in the information systems literature, knowledge management theory has suggested that information that contains unique unit-specific measures is often disregarded or not heavily valued by managers when making their decisions and performance evaluations (Lipe and Salterio 2000).

In the data quality and statistics literature (e.g., Hand 1996; Wang and Strong 1996), perceptions of the quality of data are often based on its underlying properties such as its accuracy, availability, reliability, relevance, and timeliness. However, managers have also been found to have heterogeneous and subjective beliefs on how important each underlying property is to their overall preferences of data quality (Pipino, Lee, and Wang 2002). Thus, while a manager's subjective beliefs about importance of underlying properties are expected to influence his/her preferences for certain metrics, it is unknown how much these beliefs drive managerial selection, rankings, and trade-offs between metrics in a marketing context.

Finally, to account for potential covariates that can influence managerial metric preferences and trade-offs, we turn to the marketing and management literature where scholars posit that a firm's strategy, decision making, and resource allocation are largely contingent on current firm and environmental characteristics (Donaldson 2001). For example, betterperforming firms have been found to use different information in their decisions than those who 
perform worse (Glazer and Weiss 1993). Further, characteristics of the (a) manager making the decision, i.e., his/her experience and level in the organization (Perkins and Rao 1990); (b) marketing function, i.e., its market orientation and importance to the firm (Verhoef and Leeflang 2009); (c) firm, i.e., size, B2B vs. B2C, and goods vs. service orientation (Mintz and Currim 2013); and (d) industry, i.e., market concentration and stage of life cycle (Buzzell and Gale 1987), all could potentially impact which information is considered more important to the manager.

\section{Conceptual Framework}

Based on an iterative process that combined insights garnered from common managerial practices, over 200 conducted managerial interviews, and the related literature previously discussed, we propose the following conceptual framework (see Figure 1, which is shown after the references). First, based on utility theory, we expect an individual metric to need to cross a manager's utility threshold in order to be considered. However, because previous research on consideration sets suggests that managers have limited cognitive resources and can be overwhelmed by information overload, we do not expect all metrics to cross the utility threshold. Hence, metrics that are not easily codified and understood by the manager or across the organization are less likely to be considered, in line with knowledge management theory.

Second, based on value chain theory, we expect that the manager's utility for a given metric will be contingent on the type of marketing budget decision. In other words, the utility for a metric and whether it is high enough to cross the threshold to be included for their idealized dashboard will differ by the type of marketing budget decision. Third, for metrics that cross the utility threshold, managers are expected to have rankings in terms of their preferences for these individual metrics. Based on research in the managerial accounting literature, these rankings are 
expected to differ based on whether the task is for facilitating internal decisions (within the marketing department) or external decisions (outside the marketing department) that seek management's approval.

Fourth, based on the data quality and measurement literature, we expect managerial beliefs about the importance of underlying measurement properties of metrics to impact the baseline utility and preferences for a given metric. Thus, these managerial beliefs should drive the perceived overall importance of metrics and impact the choices, rankings, and trade-offs such managers make with individual metrics. Finally, based on contingency theory, we expect past firm and marketing performance, and the characteristics of the manager, firm, marketing function, and industry to affect the baseline utility and preferences for a given metric. In other words, we expect these manager, firm, and industry characteristics to moderate the aforementioned effects.

\section{Method}

\section{Data Collection}

The empirical context we use to test our behavioral model are idealized dashboards for the common task of marketing budgeting, where managers typically have great uncertainty (Kotler and Keller 2012) and the majority of companies claim to not use best practices (Doctorow, Hoblit, and Sekhar 2009). Our empirical data collection involved a seven-step process summarized in Table 2 and detailed below (Table 2 is shown after the references). In the first step, managers were asked to indicate which of seven marketing budget decisions, listed in Table 2, they felt that they had sufficient knowledge about their firm's current budgeting practices. Out of those decisions with perceived sufficient knowledge, managers were then forced to focus on the two types of decisions they felt greatest involvement with, hereafter referred to as 
Decision 1 and Decision 2. Those who did not feel that they possessed sufficient knowledge about at least two different types of budgetary decisions were excluded from the rest of the data collection.

Second, managers participated in a menu-based, BYO choice task, which was operationalized by asking the managers to indicate which of the 26 metrics listed in Table 2 they would like to include in their idealized dashboard for Decision 1. Metrics were displayed in a randomized order, and managers were informed of the definition of dashboards and provided the definitions of each metric via a clickable hyperlink. After numerous discussions with academics, practitioners, and academic-practitioner organizations such as the Marketing Science Institute, the total number of metrics included in the study was deemed to be a compromise between not overwhelming the participating manager with too many metrics and providing a large enough set to include a diverse range of metrics. The 26 specific individual metrics included in the study were selected based on their applicability and generalizability to all seven different marketing budgetary tasks and their reported use and perceived importance in 13 previous studies on metrics in marketing (Ambler 2003; Ambler, Kokkinaki, and Puntoni 2004; Barwise and Farley 2004; Du, Kamakura, and Mela 2007; Farris et al. 2010; Hoffman and Fodor 2010; Lehmann and Reibstein 2006; Mintz, Currim, et al. 2019; Mintz, Gilbride, et al. 2019; Mintz and Currim 2013, 2015; Pauwels et al. 2009; Srinivasan, Vanhuele, and Pauwels 2010).

We employ BYO choice analysis, also called "menu-based conjoint analysis" (Liechty, Ramaswamy, and Cohen 2001), for the idealized metric-based dashboard construction because it has at least two advantages over a standard, pick-best choice-based conjoint analysis. The first is that, for our marketing budget dashboard context, the BYO choice task better aligns with what managers actually do in practice when constructing their firms' dashboards. Managers and firms 
do not typically select the best dashboard among pre-configured dashboards, as is common with consumer products, and would be formulated in a pick-best conjoint choice set, but instead more often have flexibility in deciding which metrics should be in or out of their dashboards. The second is that BYO choice tasks are substantially less taxing than pick-best conjoint tasks (e.g., Orme 2010). This is important because when managers and firms are constructing their dashboards, they must decide between considerable amounts of metrics available to them. Consequently, for our choice task, subjects were asked which of 26 metrics they would like to include in their idealized marketing budgetary BYO dashboards, which required subjects to answer 26 yes/no questions for each of the two BYO dashboards. In contrast, a pick-one conjoint would require subjects to evaluate at least 30 dashboards on 26 different attributes.

Third, managers rank-ordered the metrics that were included in their BYO dashboard for two different types of scenarios for Decision 1: (i) when the manager or their marketing function were making that type of budgetary decision (internal to marketing) and (ii) when the manager or their marketing function were seeking top management's approval for that type of budgetary decision (external to marketing). Via the inclusion of this rank-ordering task, managers were forced to make additional trade-offs for chosen metrics for a given decision and task to provide additional information on managerial preferences. Fourth, managers rated the perceived accuracy and frequency of use for the individual metrics included in their BYO dashboards. Fifth, managers repeated steps 2 through 4 for Decision 2.

Sixth, managers rated the level of importance regarding the importance of metrics overall based on their availability, reliability, relevance, accuracy, effectiveness, and update frequency. A factor analysis indicated a one-factor solution for the perception of data quality's importance: the first eigenvalue is 2.84 ; the second eigenvalue is 0.79 . Seventh, managers answered survey 
questions regarding managerial, firm, marketing, and industry covariates. We summarize the definitions, measures, and literature sources of the variables in Appendix Table 1.

\section{Managerial Sample}

To obtain managerial respondents, we collaborated with the market research firm Qualtrics. Initial screening of respondents was conducted by Qualtrics to fulfill our requirements: (i) managers were required to have decision-making responsibilities for the marketing budget for their firms, (ii) work for firms who generated $\geq \$ 1$ million in revenues, and (iii) currently hold job titles of CEO / owner, CMO, SVP / VP of marketing, director of marketing, or brand / product / marketing managers. Then, for data quality assurance purposes, we included a series of quality control checks before, during, and after managers interacted with the choice survey based on managerial qualifications, attention checks, analysis for patterned responses, use of multiple response scales (nominal, constant sum, Likert scales), and minimum completion times. Further, respondents were only paid for quality submissions, i.e., they needed to pass these aforementioned quality control checks, which were unknown to the respondents and helped motivate them to be engaged and provide truthful answers.

Our final dataset contains qualified responses from 563 managers, with $64 \%$ of the managers categorized as top-level managers in their firm (S/VP or C-level). Over half the managers $(58 \%)$ work for firms with $\geq 500$ full-time employees, and the average manager works for a firm that is slightly market oriented (5.74 on a multi-item 1-7 scale, with greater numbers indicating more market orientation). In addition, managers' indicated that they work nearly equally for $\mathrm{B} 2 \mathrm{~B}$ and $\mathrm{B} 2 \mathrm{C}(4.28$ on a $1-7$ scale with $\mathrm{B} 2 \mathrm{~B}=1$ and $\mathrm{B} 2 \mathrm{C}=7$ ) and service and goods oriented firms (4.42 on a 1-7 scale with services $=1$ and goods $=7$ ), and in industries with high (48\%) and low (52\%) market concentration and in the introductory/growth (60\%) and 
mature/declining (40\%) stages of its life cycle. However, as indicated by the standard deviations in Appendix Table 1, there was also substantial variability within these constructs.

\section{Model}

Overview. To statistically infer managerial preferences for individual metrics for idealized marketing budgeting dashboards, we propose a random utility model that fuses data from BYO choice and ranking tasks. Our unified latent utility model corrects for selection endogeneity because managers only rank the metrics that they selected in the BYO task. The integrated model allows for correlation between the BYO and ranking latent utilities and has exclusion restrictions to identify the model (Heckman 1979). Our data fusion model for BYO choice and rankings builds on Bacon and Lenk's (2012) model for fusing pick-one conjoint with ratings. However, the data fusion model proposed in this paper requires some care in setting identification restrictions and interpreting parameters because the model is invariant to affine transformations of the latent utilities for the BYO tasks and ranking tasks. To overcome this, we propose a transformation of parameters to make them invariant to the scaling of the BYO and ranking tasks.

Statistical Model. Figure 2 summarizes our empirical statistical approach (shown after references). Subject $i$ first selects two marketing budget decisions, $d_{1}$ and $d_{2}$, from a list of $D$ decisions described in the previous section. The manager selects the decisions with which he or she is most experienced and familiar. Subjects who were not familiar with two decisions exited the experiment. We treat the decision selection as exogenous to metric preference: managers select decision based on business needs and not on their metric preferences. Second, subject $i$ completes his or her BYO dashboard tasks for $d_{1}$ and $d_{2}$ by selecting any or all of $M$ metrics from 
a menu of 26 metrics. The observed variables in the BYO task are binary, i.e., either manager $i$ selects metric $m$ to be included in their dashboard or he or she does not:

$$
Y_{0, i, m, d}= \begin{cases}1 & \text { if subject } i \text { selects metric } m \text { for decision } d \\ 0 & \text { if metric } m \text { is not selected }\end{cases}
$$

The subscript " 0 " differentiates the BYO exercise and the ranking tasks. The total number of metrics that subject $i$ uses in dashboard $d$ is:

$$
n_{0, i, d}=\sum_{m=1}^{M} Y_{0, i, m, d}
$$

The standard model for BYO tasks is the multivariate probit model (Chib and Greenberg 1998; Rao and Winter 1978), which assumes that subject $i$ picks metric $m$ for his or her dashboard if the latent utility $U_{0, i, m, d}$ for metric $m$ and marketing budget decision $d$ exceeds zero:

$$
U_{0, i, m, d}>0 \text { if } Y_{0, i, m, d}=1 \text { and } U_{0, i, m, d} \leq 0 \text { if } Y_{0, i, m, d}=0
$$

Our model for the latent utilities are:

$$
U_{0, i, m, d}=\alpha_{0, m, d}+\beta_{0, m}^{\prime} x_{i}+\varepsilon_{0, i, m, d}
$$

where the intercept $\alpha_{0, m, d}$ depends on the metric and decision; $x_{i}$ is a vector of covariates for subject $i$; and $\beta_{0, m}$ is a vector of regression coefficients for metric $m$. The covariates account for the subject, firm, and industry context and these variables are constant across metrics and decisions since managers report on each of these only once. The random errors $\varepsilon_{0, i, m, d}$ are normally distributed with mean 0 , variance 1 , and correlation $\sigma_{0, m, m^{*}}$ between metric $m$ and $m^{*}$. This correlation term accounts for unobserved complimentary and substitutability effects if subsets of metrics are selected or excluded together. The error variances are set to one to identify the multivariate probit model.

Third, after the BYO task, subject $i$ completes two ranking tasks for the selected metrics in their dashboard. The rank data are defined as:

$$
Y_{t, i, m, d}=\text { Rank type } t \text { of metric } m \text { for decision } d \text { by subject } i
$$


where $t$ is 1 for internal to the marketing function tasks for making the decision, and $t$ is 2 for external focused tasks aimed at seeking top management's approval. The best metric has rank 1, the second best has rank 2, and so on. Subjects only assign ranks to the metrics that they included in the dashboard. Ties were not allowed.

We use an ordinal probit model for the ranking tasks. The latent utilities for the ranks ( $t$ $=1$ for internal and $t=2$ for external) conditional on the BYO latent utilities are:

$$
U_{t, i, m, d}=\alpha_{t, m, d}+\beta_{t, m}^{\prime} x_{i}+\varphi_{t}^{\prime} z_{t, i, m, d}+\psi_{t, m} \varepsilon_{0, i, m, d}+\varepsilon_{t, i, m, d}
$$

where $\alpha_{t, m, d}$ is the intercepts for type of ranking, metric, and decision; $x_{i}$ are the covariates in Equation (4); $\beta_{t, m}$ and $\varphi_{t}$ and are vectors of regression coefficients for each ranking task; and $z_{t, i m, d}$ are covariates that are excluded from Equation (4) since the $z$ covariates depend on the metrics and ranking tasks while $x$ covariates do not. In our application, the covariates $z_{t, i, m, d}$ are the perceived frequency that the manager uses the metric for the selected decision and the perceived accuracy of this metric when making the decision and seeking approval. The random errors $\varepsilon_{t, i, m, d}$ are mutually independent of each other and the BYO random errors and are normally distributed with mean 0 and standard deviation $\sigma_{t, m}$.

State dependence or carryover from the BYO task to the rating task is captured by the parameter $\psi_{t, m}$ for ranking tasks $t=1$ and 2 and metric $m$. This carryover parameter captures the correlation between the error terms of the BYO task and rankings, and along with the exclusion restrictions, is important in correcting for selection bias (Heckman 1979). For example, if the estimated $\psi_{t, m}$ are non-zero, which they are with our data, then endogeneity exists due to selection effects. An alternative specification would be to correlate all of the error terms in the BYO and ranking tasks, which would result in an undesirable 3,003 (78*77/2) correlations instead of the $377(26 * 25 / 2+2 * 26)$ correlations in our model. 
Latent utility models for rankings assume that the ordering of the latent utilities correspond to the ordering of the ranks. Our study has an additional complexity: subjects only rank the metrics that they selected for their dashboards, so they rank a different number of metrics. Consequently, without further restrictions, the latent utility scales would differ among subjects depending on how many metrics that they selected. For instance, if subject A selects 3 metrics and subject B selects 10 metrics, then the estimated utilities for subject A and B's second best ranked metric would be much different. To make the utility scales comparable between subjects, we use a cut-point model:

$$
\begin{array}{ccc}
U_{t, i, m, d}>\chi_{M-1} & \text { if } & Y_{t, i, m, d}=1 \text { and } Y_{0, i, m, d}=1 \\
\chi_{M-r}<U_{t, i, m, d} \leq \chi_{M-r+1} & \text { if } & Y_{t, i, m, d}=r \text { and } Y_{0, i, m, d}=1 \\
U_{t, i, M, d} \leq \chi_{1} & \text { if } & Y_{t, i, m, d}=M \text { and } Y_{0, i, m, d}=1
\end{array}
$$

where the cut-points are ordered $\chi_{1}<\ldots<\chi_{\mathrm{M}-1}$. Note that the ordering of the ranks ( 1 is best, and 2 is second best) is reversed of the ordering of the latent utilities (utility for best is bigger than the utility for second best). If subject $i$ selected less than $M$ metrics in the BYO task (i.e., all the metrics), we do not know how he or she would rank the metrics that were not selected. Thus, if the number of metrics $n_{0, i d}$ that were selected by subject $i$ is less than $M$, then the ordinal probit model for the unranked metrics is assumed to be less than the cut-point for worst-ranked metric:

$$
U_{t, i, m, d} \leq \chi_{M-n_{0, i, d}} \text { if } Y_{0, i, m, d}=0 .
$$

For the metrics that were not selected, we use multiple imputation within each iteration of the MCMC (Little and Rubin 2002). Finally, since we estimate the intercept and error standard deviation, we need to fix two of the cut-points to identify the model. We fix the first and last cut-points to -3 and 3 so that the scale of the utilities from the rank data will be roughly equivalent to that of the BYO utilities where the error variance is one. 
Because the data fusion model combines BYO utilities with rank utilities, the choice of fixed cut-points can lead to substantive differences in the results by shifting the means and variances of the latent utilities for the probit models. Some of these differences are easy to reconcile: increasing the spread in the fixed cut-points by a factor of 10 tends to increase the error standard deviations and the carryover parameter $\psi$ by a factor of 10 , and adding a constant to the fixed cut-points shifts the intercepts in the ordinal probit model. For some other results, such as comparing intercepts, parsing out the effect of the identifying constraints is more difficult. To make the results robust to identification constraints, we standardize the intercepts by dividing the intercepts by the standard deviation $\sigma_{t, m}$ of the random error and then mean centering by an ANOVA decomposition. We transform the intercepts into main effects and interactions in a 3-way ANOVA with 26 levels for metric, 7 levels for marketing decision, and 3 levels for task:

$$
\begin{aligned}
& \alpha_{t, m, d} / \sigma_{t, m}=\text { Grand Mean + Metric Main Effect + Decision Main Effect } \\
& + \text { Task Main Effect + Metric*Decision Interaction } \\
& \text { + Metric*Task Interaction + Decision*Task Interaction } \\
& \text { + Metric*Decision*Task Interaction }
\end{aligned}
$$

where the main effects and interactions sum to zero. The Appendix provides further details and presents a robustness study to verify this method.

Equations (4) and (6) imply a structured covariance for the random error terms:

$$
\left[\begin{array}{ccc}
\Sigma_{0} & \Sigma_{0} \Psi_{1} & \Sigma_{0} \Psi_{2} \\
\Psi_{1} \Sigma_{0} & \Sigma_{1}+\Psi_{1} \Sigma_{0} \Psi_{1} & \Psi_{1} \Sigma_{0} \Psi_{2} \\
\Psi_{2} \Sigma_{0} & \Psi_{2} \Sigma_{0} \Psi_{1} & \Sigma_{2}+\Psi_{2} \Sigma_{0} \Psi_{2}
\end{array}\right]
$$

where $\Psi_{t}$ and $\Sigma_{t}$ for $t=1$ and 2 are $M$ x $M$ diagonal matrices with $\psi_{t, m}$ and $\sigma_{t, m, m}$ on the diagonals. The model adjusts for selection effects by excluding the covariates $x_{i}$ from the random utility for the ranking tasks in Equation (6) and by including a correlation structure among the selection task and the two ranking tasks. We estimate this structural covariance by adapting Talhouk, 
Doucet, and Murphy (2012) method for generating correlation matrices for multivariate probit and Lenk and Orme (2009) conditional normal model.

\section{Results}

\section{Descriptive Statistics on Metrics}

The 563 marketing managers in the BYO experiment generated 1,126 dashboards: two dashboards per subject for different marketing decisions. The most frequently reported idealized marketing budget dashboards, as reported in Figure 3, Panel A (shown after the references), were for digital (277 dashboards) and traditional advertising decisions (202 dashboards). Respondents included an average of 5.8 metrics per dashboard across all marketing decisions, and dashboards ranged in total metric use from one metric to all 26 . There is some variation in the number of metrics per dashboard by marketing decision, ranging from an average 5.1 metrics for trade promotions to an average of 6.2 metrics for new product development (NPD) (Figure 3, Panel B; shown after the references). However, we do not find significant differences in the number of metrics included in BYO dashboards across types of decisions ( $\mathrm{p}=.25$ in a one-way ANOVA).

In Table 3 (shown after the references), we report, overall and by type of marketing budget decision, on each metric's percent of inclusion in BYO dashboards, average rankings for internal and external decision tasks, and rankings in comparison to the other metrics for both the percent inclusion in BYO dashboards and average rankings for internal and external tasks. In Figure 4 (shown after the references), we graph the metrics' proportion of inclusion in BYO dashboards for easier interpretability. The five individual metrics most frequently included in the BYO dashboards were satisfaction (34\%), return on investment (ROI) (33\%), net profit (32\%), loyalty (30\%), and total customers (29\%). The five metrics least often included in BYO dashboards were Tobin's Q (9\%), net promoter score (NPS) (13\%), consideration sets (13\%), net 
present value (NPV) (14\%), and share of voice (15\%). From the metrics that were included in BYO dashboards, we asked the respondents to rank their chosen metrics in terms of importance for internal and for external use. For internal decision tasks, the five metrics ranked the highest by managers were (in order) ROI, net profit, satisfaction, return on marketing investment (ROMI), and return on sales (ROS). For external decision tasks, the five metrics ranked the highest were ROI, net profit, ROS, ROMI, and likeability. For many metrics, we find similarities in their internal and external average rankings; however, some differences exist between internal and external tasks when looking at the metrics average ranking compared to others. For example, we find stock returns are ranked near the bottom of average-ranked metrics for internal tasks (ranked $21^{\text {st }}$ ), but closer to the top for external tasks (ranked $9^{\text {th }}$ ), and Tobin's Q is ranked high for internal tasks (ranked $6^{\text {th }}$ ), but ranked lower for external tasks (ranked $13^{\text {th }}$ ).

Our central expectation is that respondents' desired metrics should differ by decision and by decision tasks. A logistic regression model for selecting metrics into idealized dashboards tests if the differences are significant and confirms our central premise that metric utility varies by marketing decision. The main effects for metric, decision, and their interactions are highly significant $(\mathrm{p}<.01)$. Further, when examining the full-set of descriptive statistics in Table 3, we find several model-free differences existed, as we had hypothesized. For example, one of the biggest differences was with the measure "share of wallet." It is one of the least included metrics in BYO dashboards for traditional advertising (ranked $24^{\text {th }}$ ), digital advertising (ranked $20^{\text {th }}$ ), and new product development (ranked $24^{\text {th }}$ ) decisions, but it is included relatively more often than other metrics for trade promotion (ranked $14^{\text {th }}$ ). In addition, share of wallet is ranked relatively lower than other metrics when managers are making new product development decisions for both internal and external tasks (ranked $21^{\text {st }}$ and $26^{\text {th }}$ respectively). However, for traditional 
advertising decisions, share of wallet is ranked higher than other metrics for internal tasks (ranked $5^{\text {th }}$ ) and ranked lower than other metrics for external tasks (ranked $21^{\text {st }}$ ).

Hence, to meaningfully examine the differences in managerial preferences for metrics, we need to look across many of the different variants - type of decision, internal vs. external decisions, and by company and industry covariates. Consequently, the model-free descriptive statistics report demonstrates the need for the theory-based empirical model detailed in previous sub-sections that inter-connects how these relationships can affect managerial choices, rankings, and trade-offs between metrics.

\section{Model Results}

We estimated the model with Markov chain Monte Carlo and use "Bayesian p-values" to test if a coefficient is significant. In line with Bayesian estimation, we identify a coefficient as significant at the 0.05 level if $97.5 \%$ of its posterior distribution is above 0 or $97.5 \%$ is below 0 . Positive (negative) main effects indicate that the metric utilities in Equations (4) and (6) are larger (smaller), all else held constant; hence, these metrics are more (less) likely to be included in the BYO idealized marketing budget dashboard task or ranked higher (lower) in the ranking tasks.

Table 4 (shown after the references) displays the grand mean (upper-left cell of results), main effects for metric (first column of results), main effects for decision (first row of results), and interactions between metric and decision (second-eighth columns of results) from the threeway ANOVA decomposition in Equation (9), after scaling the standard deviation of the error

terms. In Figure 5 (shown after the references), we rank-order the main effects for metrics based on their preference weights. We find ten metrics have significant, positive main effects, with managers' most preferring satisfaction, total customers, and ROS. We also find eight metrics 
have significant, negative main effects, with managers' least preferring Tobin's Q, consideration set, and NPS. Interestingly, we find the metrics significantly preferred by managers are a mixture of non-financial or marketing (satisfaction, total customers, market share, loyalty, and retention rate) and financial metrics (ROS, target volume, net profit, ROI, and ROMI). This provides some evidence reinforcing current efforts on making firms more customer-centric, and also reflects current trends and demands that marketing needs to be more financially-oriented. We consider possible explanations and implications in the Discussion section.

Next, we report on the interactions between metrics and type of marketing budget decisions. We find 35 significant interactions out of 182 interaction terms: 23 positive and 12 negative. The positive (negative) interactions indicate that these metrics are more (less) preferred for a certain type of budgeting decision in comparison to their overall preferences to the metric and decision. For instance, we find net profit, which has a positive and significant main effect, has positive and significant interaction effects with pricing, new product development, and distribution decisions, indicating managers have greater preferences for net profit in these types of budgetary decisions. However, we also find that net profit has a significant and negative interaction with trade promotions, indicating managers have worse preferences for net profit in trade promotion budgetary decisions. In contrast, we find that NPS, which has a negative and significant main effect, has positive and significant interaction effects with traditional advertising and customer and trade promotions. Consequently, we find that although NPS is less preferred overall, it is more valued by managers making these three types of decisions. Based on the interactions, we can also examine which metrics are more or less preferred for a type of marketing budget decision. For example, we find that managers who make digital advertisement decisions have positive, significant preferences for ROMI and share 
of voice, but also negative, significant preferences for customer lifetime value (CLV), economic value added (EVA), and perceived quality of the product or brand. While we believe the interaction findings are important, due to space reasons, we refer the reader to Table 4 for more in-depth analysis of the results. ${ }^{2}$

Table 5 (shown after the references) displays the estimated coefficients $\beta_{t, m}$ for the managerial, firm, industry, marketing function, and data quality covariates in Equations (4) and (6). We find that managers who value measurement properties (Importance of Measurement) significantly prefer financial metrics such as ROMI, NPV, EVA, and CLV (first column of results in Table 5), which are metrics typically computed from enterprise resource management software and accounting databases, and not based on consumers perceptions obtained from surveys or other methods. In addition, managers who value measurement properties of metrics also significantly prefer satisfaction, quality, and retention among the marketing metrics, which are marketing metrics with more established measurement properties. Further, we find managers who value measurement properties tend to prefer financial metrics like ROI and ROS for their internal and external tasks, over marketing metrics such as likeability and preference for the brand or service (second and third column of results in Table 5). Consequently, we find that when ROI and ROS (likeability and preference) are included in BYO budgetary dashboards, they

\footnotetext{
${ }^{2}$ For the main effects by type of decision, we only find distribution to be significant and negative, which implies that dashboards for distribution decisions tend have fewer metrics than other decisions. Other types of decisions were insignificant. The main effects for type of task (BYO and ranking internal and external) are significant, but not substantively meaningful since they are artifacts of the identification of the ordinal probit model. In the Appendix, we discuss this in more detail. The only significant interaction between type of task and decision is between digital advertisement and BYO, indicating that managers making digital advertisements are significantly more likely to include more metrics in their BYO dashboard. The remaining interactions between type of task and decision are insignificant, as are the two-way interactions between metric and task, and the three-way interactions between type of task, metric, and decision. Hence, we do not report them here but the complete tables are available from the authors upon request.
} 
tend to be enhanced (downgraded) in the ranking tasks by managers who value solid measurements.

Next, we examine which metrics are valued the most by managers working in better performing firms and marketing functions. We find two significant positive coefficients for utilities in the BYO task: Tobin's Q for Recent Business Performance and share of wallet for Recent Market Performance. This reveals an interesting contrast: while Tobin's Q is found to be the managers' least preferred metric overall, at the same time, it has the most positive interaction with better performing firms. We come back to this result in the Discussion section. Further, we find that managers working in better performing marketing functions significantly prefer market share and customer segment profitability for internal tasks, but not external tasks, and that these managers prefer EVA and branding expenditures for external tasks, but not internal tasks.

For the remainder of our manager, firm, and industry covariates, we note that many of these covariates are significant, indicating their importance to be included in our conceptual and empirical models. For example, we find that (i) satisfaction, quality, and preference are valued greater in market oriented firms, (ii) ROMI is valued greater in firms where marketing has greater perceived importance to the firm; and (iii) NPS is valued greater in larger firms but less so in smaller firms. However, since we consider these manager, firm, and industry characteristics as controls, and there are too many covariates to go into details about every characteristic, we refer the reader to Table 5 for further analysis.

The latent utilities of internal and external decisions in Equation (6) have covariates that are excluded from the BYO utilities in Equation (4). Subjects rated metrics included in their idealized BYO dashboards for how frequently they used the metric for this type of budgetary decision and based on their perception of the metric's accuracy. We find that metrics more 
frequently used by managers tended to be ranked significantly higher in the ranking tasks $(p<.05)$, but the metric's perceived accuracy did not impact the rankings $(p>.05)$. Based on our previously discussed findings that managers who value measurement properties tend to select different metrics, we believe this result may occur because managers are less likely to select metrics for their idealized BYO dashboards that they consider to be inaccurate, so all metrics selected for their dashboards pass some subjective threshold of accuracy. However, this result may also occur simply because managers care less about metric accuracy when selecting metrics for their idealized BYO dashboards.

In terms of the relationship between the BYO and ranking tasks utilities, we detect considerable carryover or state dependence $\psi_{t, m}$ in Equation (6). The coefficients of $\psi_{t, m}$ are all significantly different from zero ( $\mathrm{p}<.05)$ and range between 1.21 and 1.98 with a median of 1.60 . These results are not surprising as we would expect some similarity between managerial preferences for metrics in the BYO idealized dashboard tasks and how they subsequently ranked them for the two decision tasks. However, these results demonstrate the need to incorporate these carryover effects when modeling the ranking task utilities to avoid bias due to selection effects. The carryover for internal and external decisions are broadly similar to each. The ratios of the carryover for external to internal range between 0.88 and 1.11 with a median of 0.99 . Combining this result and the lack of significant differences reported in Table 5 between preferences for metrics in internal vs. external decision tasks, suggests that managers do not appear to significantly rank metrics differently for their internal and external tasks.

Finally, we examine the correlations between expected utilities from the BYO dashboard task to assess whether metrics were selected in some type of substitutability or complimentary patterns. Overall, none of the BYO error correlations are significantly different from zero, and 
they ranged between -0.03 and 0.09 , which indicates that after adjusting for their expected utilities, subjects did not consistently select metrics in groups of substitutes or compliments. ${ }^{3}$ In other words, we find no distinctive pattern of how managers selected certain groups to be included in their idealized dashboards. This could be a result caused by a heterogeneous set of managers that cannot be captured by the covariates included in our study or simply that managers prefer to use their own portfolios of metrics tailored for their own manager, firm, and industry contexts.

\section{Discussion}

In this research, we develop a novel framework and empirical methodology to infer managerial preferences of metrics based on the selections, rankings, and trade-offs managers make when making their marketing budgetary decisions, and estimate such preferences using a large-scale managerial sample collected via surveys. Based on insights garnered from over 200 managerial interviews and a broad, multi-disciplinary literature review, we posit that managerial preference weights for metrics are a function of the type of marketing budgetary decision, the internal and external to marketing decision task, managerial perception of importance of data quality measurement, and characteristics of the manager, marketing function, firm, and industry. Our empirical results provide support for the proposed behavioral model and contributes to marketing theory by identifying broad drivers of managerial preferences for metrics by type of marketing decisions.

Consistent with our initial premise, we find managerial metric preferences do indeed depend on the specific marketing decisions being made, as reported in Table 4. However, we find less empirical support for our second premise expecting managers to value metrics

\footnotetext{
${ }^{3}$ The error variances for ranking tasks ranged from 0.89 to 1.63 with a standard deviation of 1.16.
} 
differently for internal versus external decision tasks. We also find that managers who place a greater importance on underlying data quality issues, tend to broadly prefer financial metrics over marketing metrics, and that characteristics of the manager, firm, and industry are all important aspects for marketing dashboards. Hence, our broad-level empirical results indicate that marketing dashboards need to be flexible and adapt to the decision, task, and managerial, firm, and industry characteristics at hand.

The method employed to analyze this behavioral model contributes methodologically by combining a BYO, menu-based choice task and subsequent rankings of those metrics included across a number of different types of decisions while accounting for a wide range of covariates. This combination of research methodologies allows us to combine stated and latent revealed managerial preferences from forced trade-off scenarios, which we believe will be useful for future market research. For example, our methodology would be useful for car manufacturers to try to better understand their consumers' preferences for a variety of potential car attributes, in which our method would provide more in-depth and realistic analysis. For instance, the attributes that consumers' value differ among use condition, such as commuting, road trips, and weekend adventures in nature. Similarly, hotel/resort attributes are differently valued for family stays versus romantic getaways. Our methodology is most appropriate when subjects are forced with a menu choice for a product or service, and the contingencies of the consumption experience is not uniform.

While the main focus of this research is on the underlying framework and novel methodology proposed to infer managerial preferences of metrics, our empirical results based on 563 managers describing 1,126 marketing budgeting decisions and 2,252 internal and external tasks offer useful and novel insights for managers, consultants, and marketing researchers. First, 
we provide descriptive statistics that capture current trends of which metrics are most likely to be included in idealized marketing BYO dashboards across a number of decisions and what are the rank-order of these metrics when managers are making internal and external to the marketing function tasks. For example, we find satisfaction is the metric most likely to be included in an idealized dashboard, and ROI is the metric most likely to be highest ranked for both internal and external tasks. In addition, we find that some metrics like net profit are consistently among the three highest-ranked metrics, while share of voice and consideration set are consistently among the five lowest-ranked metrics. Other metrics like loyalty have a high likelihood to be included in budgetary BYO dashboards, but have a moderate ranking for the internal and external decision tasks, indicating that managers prefer these metrics to be included in their budgetary dashboards but are less likely to rely on them for their internal or external decision tasks.

Second, our results suggest that managers have the greatest preferences or utilities for satisfaction, total customers, and ROS, and least preferences for Tobin's Q, consideration sets, and NPS. Our finding of satisfaction as the most popular measure employed by managers is consistent with previous research (e.g., Mintz, Currim, et al. 2019). However, finding lower overall managerial preferences for NPS it was a bit surprising to, especially given the amount of attention it has received over the last twenty years and that it is regularly touted as a superior metric to satisfaction (e.g., Stauffer 2019). Consequently, it appears that the message of NPS touted as a superior metric has not been widely heard and/or accepted. In addition, when looking at the lowest preferred metrics, interestingly, it appears that marketers' attention seems to focus on the metrics they believe they can directly affect and not so grandiose to follow all the way to stock market returns. 
Third, we find that managers who perceive data quality as an important quality of metrics, tend to broadly prefer financial metrics over marketing metrics. A possible reason for this result is that financial metrics are more widely accepted and employed by managers across the organization, so there is less uncertainty in the information that these metrics are supposed to convey. In addition, managers may be more uncertain of the information that marketing metrics convey, or less trusting of their potential impact, which lead managers with greater preference for data quality to value these marketing metrics less. These preferences for financial metrics by managers who are more concerned about measurement issues provides support for the marketing field's push for marketers to tie reasons for their marketing decisions with financial metrics (e.g., Magill, Moorman, and Avdiushko 2019). Further, it was quite clear in our analysis that marketing managers are using and need to use financial metrics for their decisions (ROI, ROMI, Net Profit, and ROS).

Finally, we find that managers in better-performing organizations value Tobin's $Q$ and share of wallet significantly greater than other metrics, which offers some best-practices based normative takeaways. This demonstrates that if we as academics believe that these are the right metrics for managers to employ for their marketing decisions, we need to continue promoting and making a better case for managers to use them. For Tobin's Q, we find less managerial preference for this metric because it is the least likely metric to be included by managers in an idealized BYO dashboard. Yet, it is also one of two metrics significantly more preferred by managers working in better performing organizations, and it has a very high ranking for internal decision tasks especially in comparison to its likelihood of being included in the BYO dashboards. Hence, it appears that those few managers who do employ it their idealized BYO dashboards, very much value it. Consequently, while Tobin's $Q$ has generally been accepted in 
the academic literature, it is less understood and/or accepted in practice. Instead, there appears to be much work to gain its acceptance by the majority of managers making marketing budget decisions, as there does appear to be some type of normative value placed on it by managers.

Overall, the empirical findings presented in our research should be useful for dashboard construct in the future since they are based on managerial preferences to metrics in idealized marketing budget dashboard situations, and hence provide normative preferences for which metrics managers most and least prefer. Further, our empirical analysis is one of the first to employ conjoint analysis to infer marketing managers' preferences. As marketers have consistently stated that less is known on marketing manager behavior (Goldfarb et al. 2012; Wierenga, Van Bruggen, and Staelin 1999), our empirical and statistical strategy can provide a guide for how such studies on managerial behavior can be conducted. However, a caveat to our research that enables future research opportunities is that our results could be a function of the sample of managers that we obtained for the data collection. While every effort was made to obtain a wide range of managers who were tasked with marketing budget decisions in their firms, our sample of managers based on a Qualtrics panel may not be representative of the managerial population as a whole. In addition, our focus was on managers working in larger firms, i.e., $\geq \$ 1$ million in revenues, but it would be interesting to compare the results of our analysis with managers working in smaller firms. Future research should also compare and contrast metric preferences for non-budgetary and budgetary decisions. This could provide insights into how metric preferences could vary between more routine and more in-depth, consequential decisions. Future work should also investigate group decision-making settings rather than focusing on the individual. Finally, our research examines managerial preferences of marketing metrics when managers are making marketing budgeting decisions, i.e., ex-ante to the decision being 
implemented. Future research should examine ex-post performance evaluations. We hope research will expand on these promising endeavors to relieve managers feeling they are "drowning in metrics." While, we do not anticipate that the "sea of metrics" will evaporate to a more manageable puddle given ever-expanding information technology, we do hope our research and similar efforts help mangers navigate and keep their heads above water. 


\section{APPENDIX}

A challenge of combining the $\mathrm{BYO}$ and ranking data for the dashboards is that the utilities for the different tasks need not have the same scale, depending on how the models are identified. Then apparent differences between the models may be an artifact of the scaling methods and not reflective of the managers' underlying preferences. The utilities for probit models are not identified because linear transformations give equivalent probability models. For instance, if the random utility $U$ has mean $\mu$ and standard deviation $\sigma$, then $U^{*}=a+b U$ has mean $\mu^{*}=a+b \mu$ and standard deviation $\sigma^{*}=b \sigma$ for constants $a$ and $b$ where $b$ is positive. Then $U$ and $U^{*}$ have the same ordering. The utilities for the BYO conjoint are identified by setting the no-choice utility to zero and the variances to one. One way to identify the ordinal probit model is to fix the first and last cut-points, which determines the location and scale of the latent utilities. Changing these fixed cut-points is equivalent to a linear transformation of the rank utilities. Because the model combines BYO utilities with rank utilities, the choice of fixed cut-points can lead to substantive differences in the results by shifting the means and variances of the latent utilities for the probit model. Some of these differences are easy to reconcile: increasing the spread in the fixed cut-points by a factor of 10 tends to increase the error standard deviations and the carryover parameter $\psi$ by a factor of 10 , and adding a constant to the fixed cut-points shifts the intercepts. Other results, such as comparing coefficients across BYO and rank tasks, are more difficult to parse out the effect of the identifying constraints. In reporting the results, we divide the intercepts by the error standard deviation and mean-center them so that they are invariant to linear transformations. Because we do not compare regression coefficients $\beta$ and $\varphi$ from the BYO and rank utilities, we do not scale them. 
We performed a small study to illustrate the impact of the fixed cut-points on the intercepts using the survey data. Appendix Table 2 shows the root mean square error (RMSE) between estimated parameters for four different assumptions about the fixed points for the ordinal probit model. Model 1 sets the fixed cut-points to -3 and 3 . With these fixed cut-points the scale of the utilities from the rank data will be roughly equivalent to that of the BYO utilities, which has error standard deviation of one. Models 2 and 3 increase the overall mean and standard deviation by setting the first cut-point to one and the last cut-point to 10 or 100 . Model 4 compresses the standard deviation by setting the cut-points to zero and one. We see that the RMSE between the raw intercepts for different models is large compared to that of the meancentered and scaled estimates. Model 4, which constrains 24 metrics between zero and one, deserves special attention. It forces the rank utilities to have a small error variance. The posterior variance of the scaled estimates was unexpectedly large after dividing by small, error standard deviations. This increase in posterior variance made it more difficult to compare parameters with confidence. In the following analysis, we use Model 1 where the fixed cutpoints are \pm 3 because the rank utilities have a similar scale to the BYO utilities.

In our analysis of the experiment the main effects for the type of task are significant $(\mathrm{p}<0.05)$ but not substantively meaningful. The main effects are -0.823 for BYO, 0.403 for Internal and 0.420 for External. The negative main effect for BYO means that metrics have less than a 50\% chance of selection into a dashboard on average. The difference between BYO and the ranking tasks are determined by the selection of fixed cut-points $( \pm 3)$ for the ordinal probit model and are not meaningful. The main effects for Internal and External are essentially equal because both use a ranking from 1 to the number of metrics selected in the BYO task. 


\section{References}

Abramson, Charles, Imran S. Currim, and Rakesh Sarin (2005), “An Experimental Investigation of the Impact of Information on Competitive Decision Making," Management Science, $51(2), 195-207$.

Ambler, Tim (2003), Marketing and the Bottom Line: The Marketing Metrics to Pump Up Cash Flow, London: FT Prentice Hall.

---, Flora Kokkinaki, and Stefano Puntoni (2004), “Assessing Marketing Performance: Reasons for Metrics Selection," Journal of Marketing Management, 20 (3), 475-98.

--- and John H. Roberts (2008), “Assessing Marketing Performance: Don't Settle for a Silver Metric," Journal of Marketing Management, 24 (7-8), 733-50.

Atuahene-Gima, Kwaku and Janet Y. Murray (2004), "Antecedents and Outcomes of Marketing Strategy Comprehensiveness," Journal of Marketing, 68 (4), 33-46.

Bacon, Lynd and Peter Lenk (2012), "Augmenting discrete-choice data to identify common preference scales for inter-subject analyses," Quantitative Marketing and Economics, 10 (4), 453-74.

Barwise, Patrick and John U. Farley (2004), "Marketing Metrics: Status of Six Metrics in Five Countries," European Management Journal, 22 (3), 257-62.

Bettman, James R., Mary Frances Luce, and John W. Payne (1998), "Constructive Consumer Choice Processes," Journal of Consumer Research, 25 (3), 187-217.

Buzzell, Robert D. and Bradley T. Gale (1987), The PIMS Principles: Linking Strategy to Performance, New York: Free Press.

Chib, Siddhartha and Edward Greenberg (1998), "Analysis of Multivariate Probit Models," Biometrika, 85 (2), 347-61.

Demski, Joel S. and Gerald A. Feltham (1976), Cost Determination: A Conceptual Approach, Ames, Iowa: Iowa State Press.

Deshpandé, Rohit and Gerald Zaltman (1982), "Factors Affecting the Use of Market Research Information: A Path Analysis," Journal of Marketing Research, 19 (1), 14-31.

--- and --- (1984), “A Comparison of Factors Affecting Researcher and Manager Perceptions of Market Research Use," Journal of Marketing Research, 21 (1), 32-38.

Doctorow, David, Robert Hoblit, and Archana Sekhar (2009), "Measuring marketing: McKinsey Global Survey Results," McKinsey Quarterly.com.

Donaldson, Lex (2001), The Contingency Theory of Organizations, Thousand Oaks, California: Sage Publications. 
Du, Rex Yuxing, Wagner A. Kamakura, and Carl F. Mela (2007), "Size and Share of Customer Wallet," Journal of Marketing, 71 (2), 94-113.

Farris, Paul W., Neil T. Bendle, Phillip E. Pfeifer, and David J. Reibstein (2010), Marketing Metrics: The Definitive Guide to Measuring Marketing Performance, Upper Saddle River, New Jersey: Wharton School Publishing.

Frösén, Johanna, Jukka Luoma, Matti Jaakkola, Henrikki Tikkanen, and Jaakko Aspara (2016), "What Counts Versus What Can Be Counted: The Complex Interplay of Market Orientation and Marketing Performance Measurement," Journal of Marketing, 80 (3), 60-78.

Gebhardt, Gary F., Francis J. Farrelly, and Jodie Conduit (2019), “Market Intelligence Dissemination Practices," Journal of Marketing, 83 (3), 72-90.

Glazer, Rashi, Joel H. Steckel, and Russell S. Winer (1992), "Locally Rational Decision Making: the Distracting Effect of Information on Managerial Performance," Management Science, 38 (2), 212-26.

--- and Allen M. Weiss (1993), "Marketing in Turbulent Environments: Decision Processes and the Time-Sensitivity of Information," Journal of Marketing Research, 30 (4), 509-21.

Goldfarb, Avi, Teck-Hua Ho, Wilfred Amaldoss, Alexander L. Brown, Yan Chen, Tony Haitao Cui, Alberto Galasso, Tanjim Hossain, Ming Hsu, Noah Lim, Mo Xiao, and Botao Yang (2012), "Behavioral models of managerial decision-making," Marketing Letters, 23 (2), 405-21.

Hand, D. J. (1996), "Statistics and the Theory of Measurement," Journal of the Royal Statistical Society. Series A (Statistics in Society), 159 (3), 445-92.

Hauser, John H. and Birger Wernerfelt (1990), “An Evaluation Cost Model of Consideration Sets," Journal of Consumer Research, 16 (4), 393-408.

Heckman, James J. (1979), "Sample Selection Bias as a Specification Error," Econometrica, 47 (1), 153-61.

Hoffman, Donna L. and Marek Fodor (2010), "Can You Measure the ROI of Your Social Media Marketing?," MIT Sloan Management Review, 52 (1), 41-49.

Homburg, Christian, Martin Artz, and Jan Wieseke (2012), "Marketing Performance Measurement Systems: Does Comprehensiveness Really Improve Performance?," Journal of Marketing, 76 (3), 56-77.

Hult, G. Tomas M., Forrest V. Morgeson, Neil A. Morgan, Sunil Mithas, and Claes Fornell (2017), "Do managers know what their customers think and why?," Journal of the Academy of Marketing Science, 45 (1), 37-54. 
Jacoby, Jacob, Robert W. Chestnut, and William A. Fisher (1978), "A Behavioral Process Approach to Information Acquisition in Nondurable Purchasing," Journal of Marketing Research, 15 (4), 532-44.

Kotler, Philip and Kevin Lane Keller (2012), Marketing Management, Upper Saddle River, New Jersey: Pearson Prentice Hall.

Lee, Hanjoon, Frank Acito, and Ralph L. Day (1987), "Evaluation and Use of Marketing Research by Decision Makers: A Behavioral Simulation," Journal of Marketing Research, 24 (2), 187-96.

Lehmann, Donald R. and David J. Reibstein (2006), Marketing Metrics and Financial Performance, Relevant Knowledge Series, Cambridge, Massachusetts: Marketing Science Institute.

Lenk, Peter and Bryan Orme (2009), "The Value of Informative Priors in Bayesian Inference with Sparse Data," Journal of Marketing Research, 46 (6), 832-45.

Liechty, John, Venkatram Ramaswamy, and Steven H. Cohen (2001), "Choice Menus for Mass Customization: An Experimental Approach for Analyzing Customer Demand with an Application to a Web-Based Information Service," Journal of Marketing Research, 38 (2), 183-96.

Lipe, Marlys Gascho and Steven E. Salterio (2000), "The Balanced Scorecard: Judgmental Effects of Common and Unique Performance Measures," Accounting Review, 75 (3), 283-98.

Little, Roderick J. A. and Donald B. Rubin (2002), Statistical Analysis with Missing Data, Hoboken, NJ: Wiley \& Sons.

Magill, Paul, Christine Moorman, and Nikita Avdiushko (2019), "8 Ways Marketers Can Show Their Work’s Financial Results," Harvard Business Review.

Malhotra, Naresh K. (1982), "Information Load and Consumer Decision Making," Journal of Consumer Research, 8 (4), 419-30.

Menon, Anil, Sundar G. Bharadwaj, Phani Tej Adidam, and Steven W. Edison (1999), "Antecedents and Consequences of Marketing Strategy Making: A Model and a Test," Journal of Marketing, 63 (2), 18-40.

--- and P. Rajan Varadarajan (1992), "A Model of Marketing Knowledge Use within Firms," Journal of Marketing, 56 (4), 53-71.

Miller, George A. (1956), “The Magical Number Seven, Plus or Minus Two: Some Limits on our Capacity for Processing Information,” Psychological Review, 63 (2), 81-97. 
Mintz, Ofer and Imran S. Currim (2013), "What Drives Managerial Use of Marketing and Financial Metrics and Does Metric Use Affect Performance of Marketing-Mix Activities?," Journal of Marketing, 77 (2), 17-40.

--- and --- (2015), “When Does Metric Use Matter Less?: How Firm and Managerial Characteristics Moderate the Relationship between Metric Use and Marketing Mix Performance," European Journal of Marketing, 49 (11/12), 1809-56.

---, ---, Jan-Benedict E. M. Steenkamp, and Martijn G. De Jong (2019), “Managerial Metric Use in Marketing Decisions across 16 Countries: A Cultural Perspective," Journal of International Business Studies, Forthcoming.

---, Timothy J. Gilbride, Imran S. Currim, and Peter J. Lenk (2019), "Right Metric for the Right Decision: A Behavioral Model to Infer Metric Effectiveness in Managerial MarketingMix Decision-Making," Working Paper, Marketing Science Institute.

Moe, Wendy W. (2014), “Coping With Metrics Overload,” Wharton Magazine.

Moorman, Christine (1995), “Organizational Market Information Processes: Cultural Antecedents and New Product Outcomes," Journal of Marketing Research, 32 (3), 31835 .

--- and George S. Day (2016), “Organizing for Marketing Excellence,” Journal of Marketing, 80 (6), 6-35.

Morgan, Neil A., Eugene W. Anderson, and Vikas Mittal (2005), “Understanding Firms' Customer Satisfaction Information Usage,” Journal of Marketing, 69 (3), 131-51.

Olson, Jerry C. and Jacob Jacoby (1972), "Cue Utilization in the Quality Perception Process," ACR Special Volumes, SV-02.

Orme, Bryan (2010), "Menu-Based Choice Modeling Using Traditional Tools," Research Paper Series, Sawtooth Software.

O’Sullivan, Don and Andrew V. Abela (2007), "Marketing Performance Measurement Ability and Firm Performance," Journal of Marketing, 71 (2), 79-93.

Pauwels, Koen, Tim Ambler, Bruce H. Clark, Pat LaPointe, David J. Reibstein, Bernd Skiera, Berend Wierenga, and Thorsten Wiesel (2009), "Dashboards as a Service: Why, What, How, and What Research Is Needed?," Journal of Service Research, 12 (2), 175-89.

Perkins, W. Steven and Ram C. Rao (1990), "The Role of Experience in Information Use and Decision Making by Marketing Managers," Journal of Marketing Research, 27 (1), 1-10.

Petersen, J. Andrew, Leigh McAlister, David J. Reibstein, Russell S. Winer, V. Kumar, and Geoff Atkinson (2009), "Choosing the Right Metrics to Maximize Profitability and Shareholder Value,” Journal of Retailing, 85 (1), 95-111. 
Pipino, Leo L., Yang W. Lee, and Richard Y. Wang (2002), "Data Quality Assessment," Communications of the ACM, 45 (4), 211-218.

Rao, Vithala R. and Frederick W. Winter (1978), "An Application of the Multivariate Probit Model to Market Segmentation and Product Design," Journal of Marketing Research, 15 (3), 361-68.

Roberts, John H. and James M. Lattin (1991), "Development and Testing of a Model of Consideration Set Composition," Journal of Marketing Research, 28 (4), 429-40.

See, Ed (2007), “Move From Metrics Overload to Actionable Insights," AdAge.

Simon, Herbert A. (1956), "Rational Choice and the Structure of the Environment," Psychological Review, 63 (2), 129-38.

Sinkula, James M. (1994), "Market Information Processing and Organizational Learning," Journal of Marketing, 58 (1), 35-45.

---, William E. Baker, and Thomas Noordewier (1997), “A framework for market-based organizational learning: Linking values, knowledge, and behavior," Journal of the Academy of Marketing Science, 25 (4), 305-18.

Sprinkle, Geoffrey B. (2003), "Perspectives on Experimental Research in Managerial Accounting," Accounting, Organizations and Society, 28 (2-3), 287-318.

Srinivasan, Shuba and Dominique M. Hanssens (2009), "Marketing and Firm Value: Metrics, Methods, Findings, and Future Directions," Journal of Marketing Research, 46 (3), 293312.

---, Marc Vanhuele, and Koen Pauwels (2010), "Mind-Set Metrics in Market Response Models: An Integrative Approach,” Journal of Marketing Research, 47 (4), 672-84.

Stauffer, Brian (2019), “The Dubious Management Fad Sweeping Corporate America,” Wall Street Journal.

Talhouk, Aline, Arnaud Doucet, and Kevin Murphy (2012), "Efficient Bayesian Inference for Multivariate Probit Models With Sparse Inverse Correlation Matrices," Journal of Computational and Graphical Statistics, 21 (3), 739-57.

Venkatesan, Rajkumar (2017), "Executing on a customer engagement strategy," Journal of the Academy of Marketing Science, 45 (3), 289-93.

Verhoef, Peter C. and Peter S. H. Leeflang (2009), “Understanding the Marketing Department's Influence Within the Firm," Journal of Marketing, 73 (2), 14-37.

Wang, Richard Y. and Diane M. Strong (1996), "Beyond Accuracy: What Data Quality Means to Data Consumers,” Journal of Management Information Systems, 12 (4), 5-33. 
Wierenga, Berend, Gerrit H. Van Bruggen, and Richard Staelin (1999), "The Success of Marketing Management Support Systems," Marketing Science, 18 (3), 196. 


\section{Figure 1. Conceptual Model}

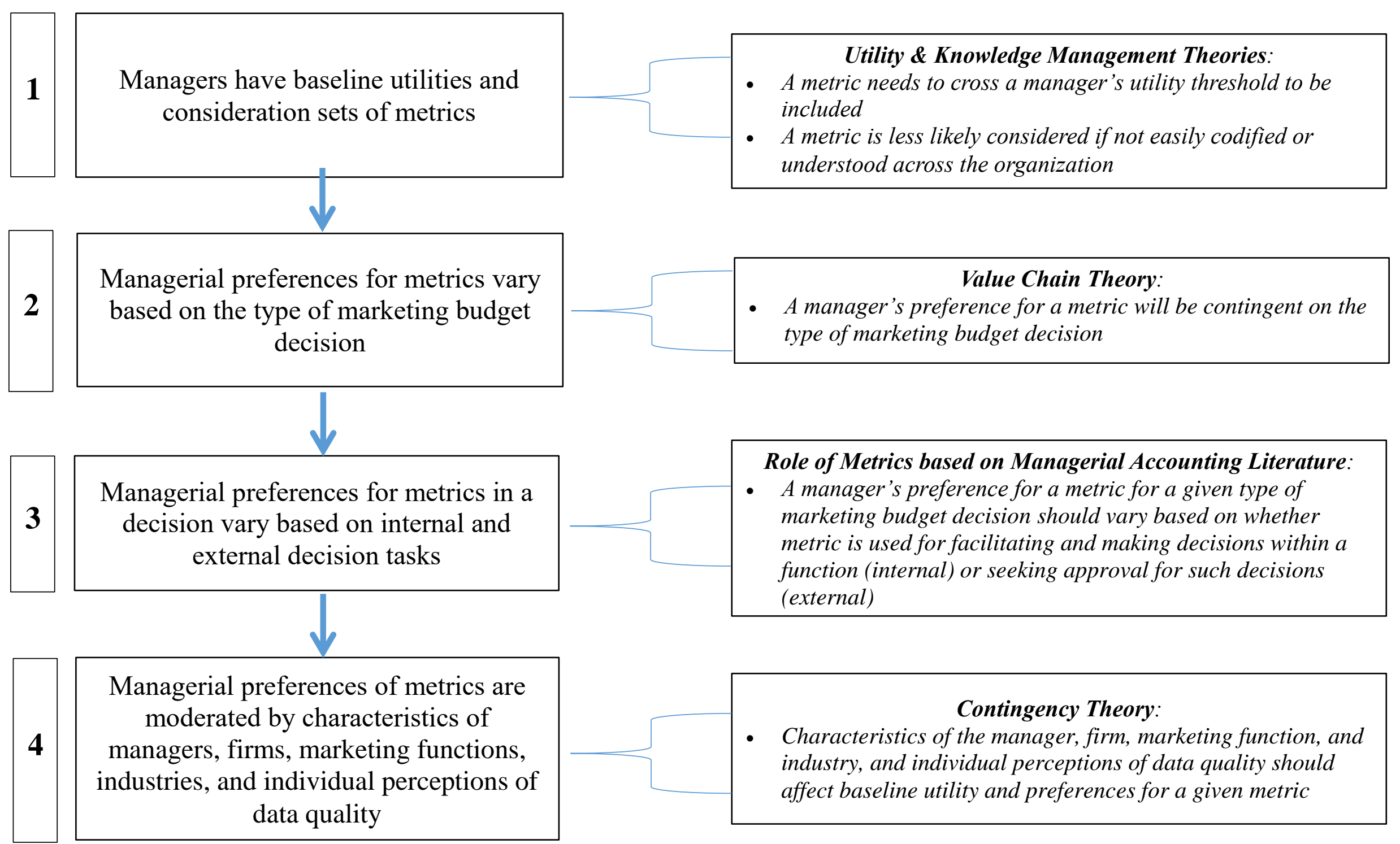


Figure 2. Statistical - Empirical Model

Marketing Decision

- Traditional Advertising

- Digital Advertising

- Consumer Promotions

- Trade Promotions

- Pricing

- New Product Development

- Distribution

Manager

- Measurement Importance

- Work Experience

- Marketing Responsibility Firm

- Recent Business Performance

- Marketing Performance

- Market Orientation

- Marketing Importance

- Top Marketing Manager

- Goods vs Service

- BzB vs B2C

- Firm Size

Industry

- Market Concentration

- Life Cycle

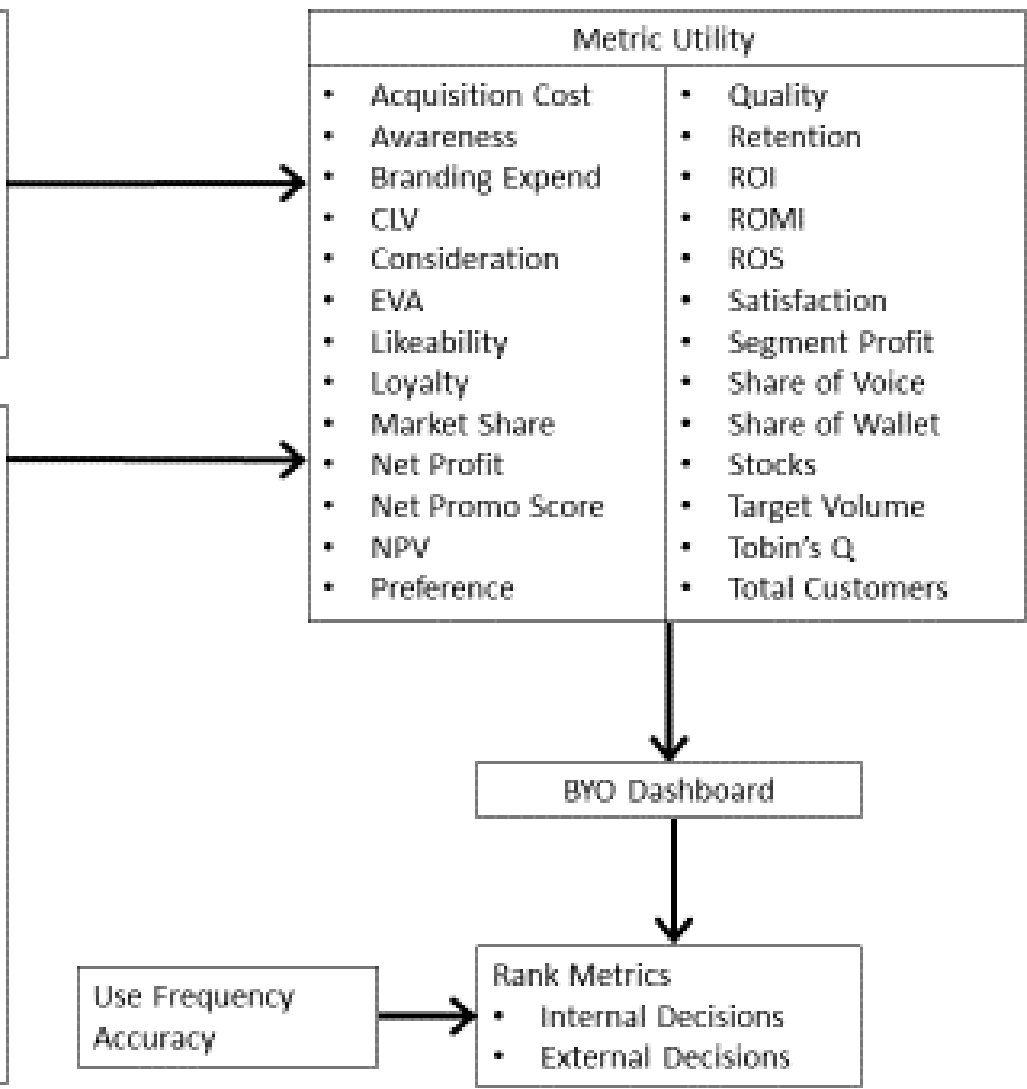


Figure 3. Summary Statistics on Dashboards by Type of Marketing Budget Decision

Panel A. Shares and Number of Types of Marketing Budget Decisions

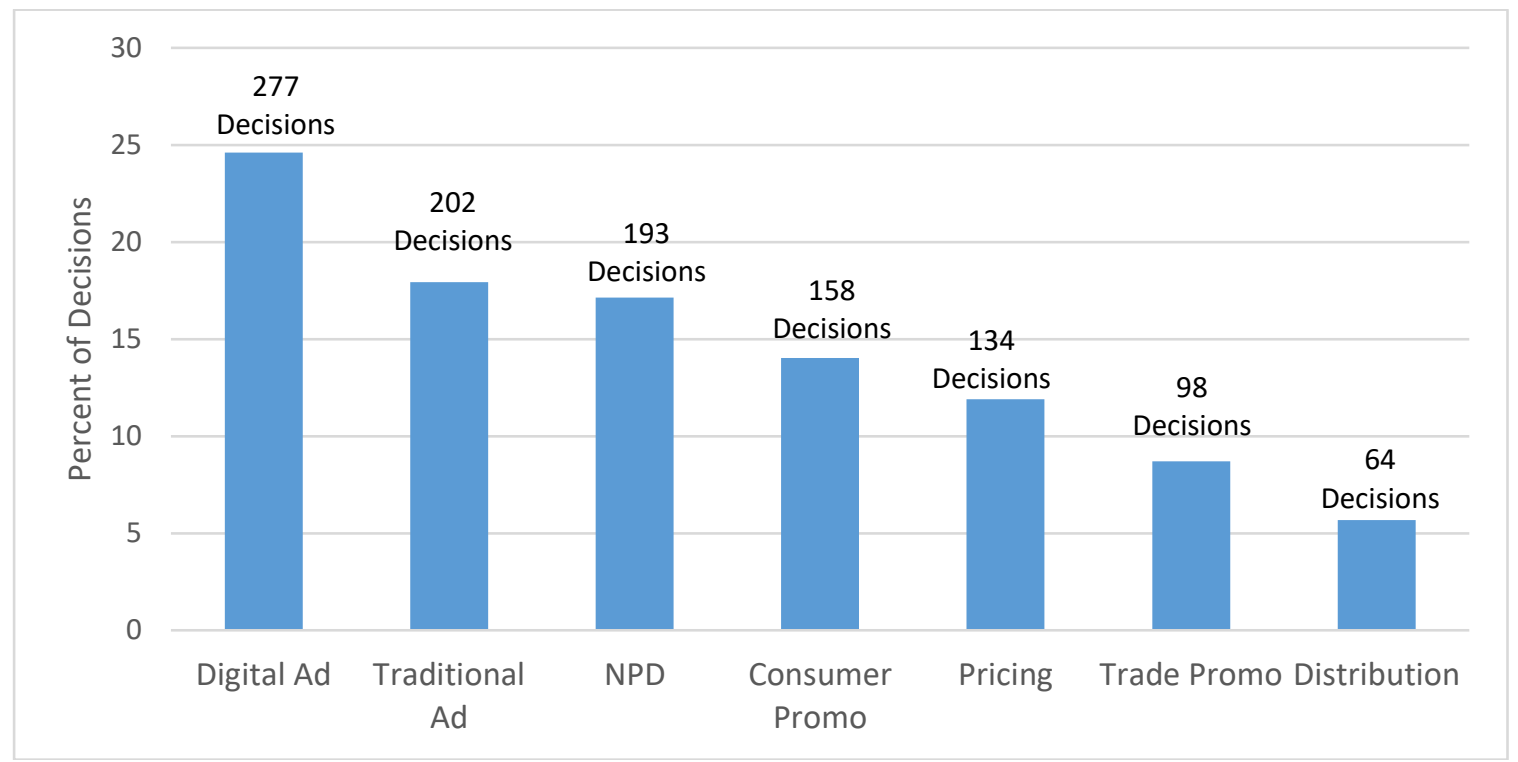

Panel B. Boxplots of Number of Metrics per Dashboard by Marketing Decision

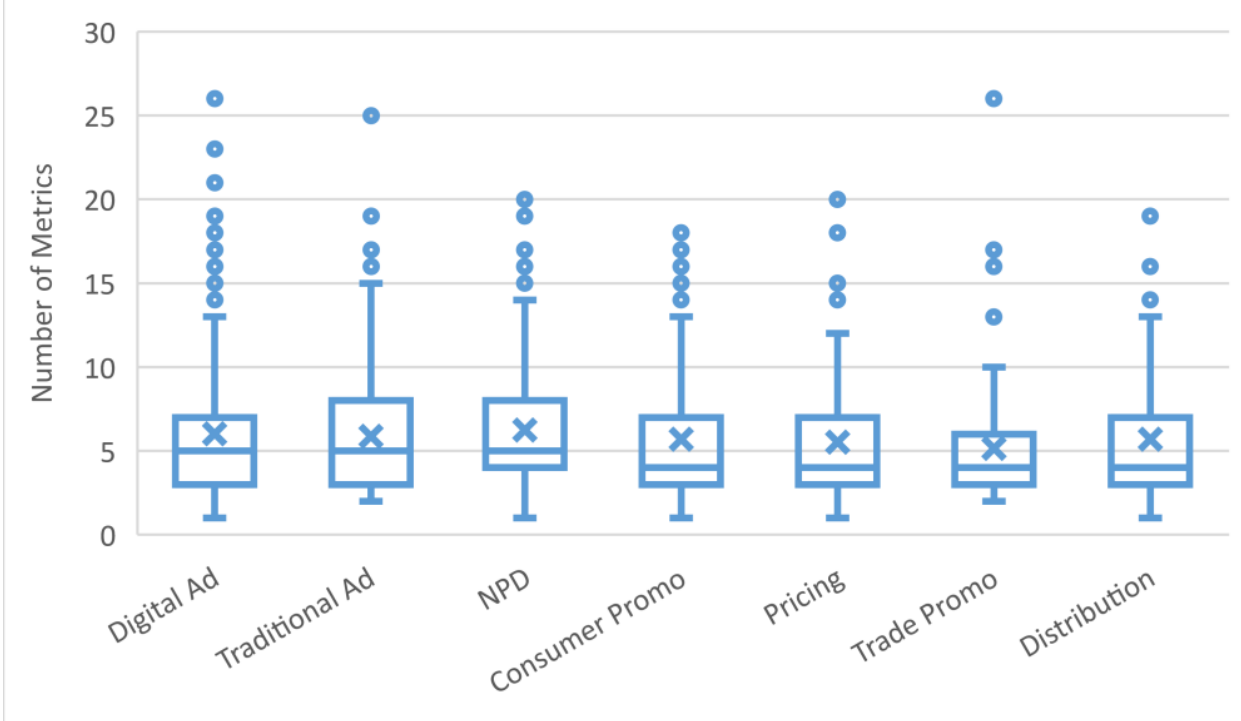


Figure 4. Metric's Percent of Inclusion in BYO Dashboards Overall and by Decision

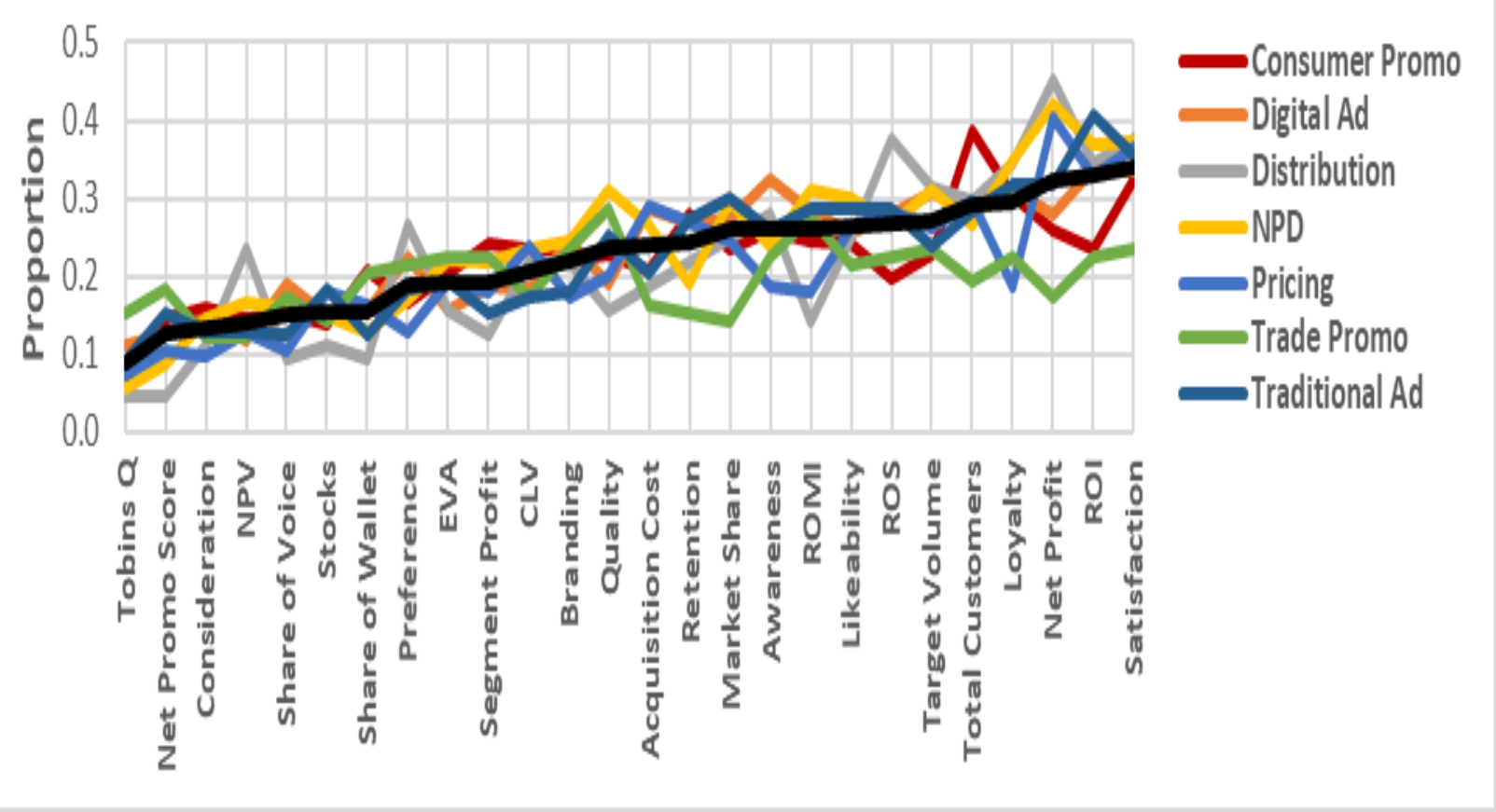


Figure 5. Main Effects for Metrics

\section{Effects}
$-1.4$
$-1.2$
$-1$
$-0.8$
$-0.6$
$-0.4$
$-0.2$
O
0.2
0.4
0.6
0.8

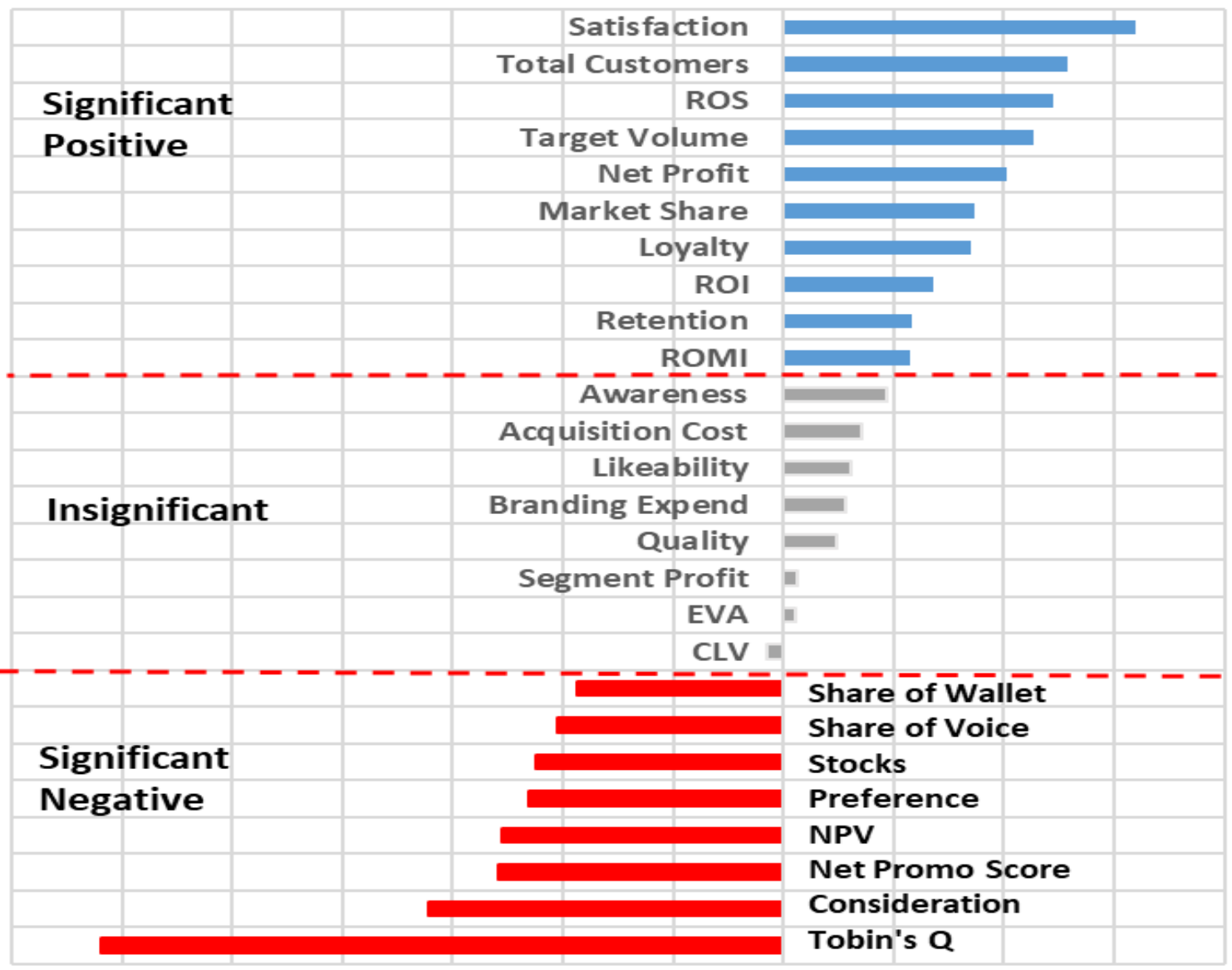


Table 1. Summary of Related Literature in Managerial Metric or Information Use for Marketing Decisions

\begin{tabular}{|c|c|c|c|c|c|}
\hline Authors & $\begin{array}{c}\text { Examines } \\
\text { Individual or } \\
\text { Aggregate } \\
\text { Metric Use }\end{array}$ & $\begin{array}{l}\text { Examines } \\
\text { Metrics by } \\
\text { Decision } \\
\text { Type }\end{array}$ & \begin{tabular}{|c|} 
Examines \\
Preferences of \\
Individual \\
Metrics by \\
Decision Task \\
\end{tabular} & \begin{tabular}{|c|} 
Examines \\
Trade-Offs in \\
Information \\
Managers \\
Employ \\
\end{tabular} & Summary \\
\hline $\begin{array}{l}\text { Abramson et al. } \\
(2005)\end{array}$ & Aggregate & & & & $\begin{array}{l}\text { Examines whether additional } \\
\text { information and decision aids improve } \\
\text { marketing-mix decision outcomes }\end{array}$ \\
\hline Ambler (2003) & Individual & $\sqrt{ }$ & & & $\begin{array}{l}\text { Suggests different individual metrics to } \\
\text { employ for different types of decisions }\end{array}$ \\
\hline $\begin{array}{l}\text { Ambler et al. } \\
(2004)\end{array}$ & Individual & & & & $\begin{array}{l}\text { Examines the use of metrics in the } \\
\text { United Kingdom }\end{array}$ \\
\hline $\begin{array}{l}\text { Atuahene-Gima } \\
\text { and Murray } \\
\text { (2004) }\end{array}$ & Aggregate & & & & $\begin{array}{l}\text { Examines drivers and outcomes of } \\
\text { marketing performance measurement } \\
\text { systems }\end{array}$ \\
\hline $\begin{array}{l}\text { Barwise and } \\
\text { Farley (2004) }\end{array}$ & Individual & & & & $\begin{array}{l}\text { Reports how often six metrics are } \\
\text { reported to the board of directors in } \\
\text { five countries }\end{array}$ \\
\hline $\begin{array}{l}\text { Deshpandé and } \\
\text { Zaltman (1982) }\end{array}$ & Aggregate & & & & $\begin{array}{l}\text { Examines when managers are more } \\
\text { likely to use market researcher } \\
\text { supplied information }\end{array}$ \\
\hline $\begin{array}{l}\text { Deshpandé and } \\
\text { Zaltman (1984) }\end{array}$ & Aggregate & & & & $\begin{array}{l}\text { Examines what affects market research } \\
\text { suppliers' perceptions of managerial } \\
\text { use of their information }\end{array}$ \\
\hline $\begin{array}{l}\text { Farris et al. } \\
(2010)\end{array}$ & Individual & $\sqrt{ }$ & & & $\begin{array}{l}\text { Suggests different metrics to employ } \\
\text { for different types of decisions }\end{array}$ \\
\hline $\begin{array}{l}\text { Frösén et al. } \\
(2016)\end{array}$ & Aggregate & & & & $\begin{array}{l}\text { Investigates how interactions among } \\
\text { market orientation, marketing } \\
\text { performance measurement systems, } \\
\text { and firm size affect firm profits }\end{array}$ \\
\hline $\begin{array}{l}\text { Gebhardt et al. } \\
\text { (2019) }\end{array}$ & Aggregate & & & & $\begin{array}{l}\text { Finds that creation, existence, or } \\
\text { absence of organizationally shared } \\
\text { schemes influence firms' market } \\
\text { intelligence dissemination practices }\end{array}$ \\
\hline $\begin{array}{l}\text { Glazer et al. } \\
(1992)\end{array}$ & Aggregate & & & & $\begin{array}{l}\text { Investigates whether providing } \\
\text { additional information for decision } \\
\text { making helps performance }\end{array}$ \\
\hline $\begin{array}{l}\text { Glazer and } \\
\text { Weiss (1993) }\end{array}$ & Aggregate & & & & $\begin{array}{l}\text { Examines how industry turbulence may } \\
\text { influence amount of information used } \\
\text { and associated performance }\end{array}$ \\
\hline $\begin{array}{l}\text { Homburg et al. } \\
(2012)\end{array}$ & Aggregate & & & & $\begin{array}{l}\text { Examines the impact of interactions } \\
\text { among marketing performance } \\
\text { measurement systems, the firm, and } \\
\text { the industry on firm performance }\end{array}$ \\
\hline $\begin{array}{l}\text { Hult et al. } \\
(2017)\end{array}$ & Individual & & & & $\begin{array}{l}\text { Investigates whether managers' } \\
\text { perceptions of drivers of customers' } \\
\text { satisfaction and loyalty align with } \\
\text { actual customers }\end{array}$ \\
\hline $\begin{array}{l}\text { Lee et al. } \\
(1987)\end{array}$ & Aggregate & & & & $\begin{array}{l}\text { Identifies conditions that make } \\
\text { managers more likely to use market } \\
\text { researcher supplied information }\end{array}$ \\
\hline
\end{tabular}




\begin{tabular}{|c|c|c|c|c|c|}
\hline $\begin{array}{l}\text { Lehmann and } \\
\text { Reibstein } \\
\text { (2006) }\end{array}$ & Aggregate & $\sqrt{ }$ & & & $\begin{array}{l}\text { Provides guidance for metrics selection } \\
\text { based on type of decision and manager }\end{array}$ \\
\hline $\begin{array}{l}\text { Menon and } \\
\text { Varadarajan } \\
(1992)\end{array}$ & Aggregate & & & & $\begin{array}{l}\text { Develops conceptual model to untangle } \\
\text { how environment, task, firm, and } \\
\text { manager characteristics influence } \\
\text { knowledge utilization }\end{array}$ \\
\hline $\begin{array}{l}\text { Menon et al. } \\
(1999)\end{array}$ & Aggregate & & & & $\begin{array}{l}\text { Examines the impact of firm resources } \\
\text { and culture on information use for } \\
\text { marketing strategy performance } \\
\text { measurement systems }\end{array}$ \\
\hline $\begin{array}{l}\text { Mintz and } \\
\text { Currim (2013) }\end{array}$ & Aggregate & $\sqrt{ }$ & & & Identifies drivers of overall metric use \\
\hline $\begin{array}{l}\text { Mintz and } \\
\text { Currim (2015) }\end{array}$ & Aggregate & $\sqrt{ }$ & & & $\begin{array}{l}\text { Investigates the role of total metric use } \\
\text { in marketing-mix performance }\end{array}$ \\
\hline $\begin{array}{l}\text { Mintz et al. } \\
(2019 a)\end{array}$ & Individual & $\sqrt{ }$ & & & $\begin{array}{l}\text { Investigates which individual metrics } \\
\text { are associated with better performance } \\
\text { when employed for different types of } \\
\text { marketing-mix decisions }\end{array}$ \\
\hline $\begin{array}{l}\text { Mintz et al. } \\
(2019 b)\end{array}$ & Aggregate & $\sqrt{ }$ & & & $\begin{array}{l}\text { Examines how national and } \\
\text { organizational culture influence overall } \\
\text { metric use }\end{array}$ \\
\hline $\begin{array}{l}\text { Moorman } \\
(1995)\end{array}$ & Aggregate & & & & $\begin{array}{l}\text { Discusses how organizational culture } \\
\text { may affect available and used } \\
\text { information }\end{array}$ \\
\hline $\begin{array}{l}\text { Morgan et al. } \\
(2005)\end{array}$ & Individual & & & & $\begin{array}{l}\text { Uncovers antecedents of the use of } \\
\text { customer satisfaction data }\end{array}$ \\
\hline $\begin{array}{l}\text { O'Sullivan and } \\
\text { Abela (2007) }\end{array}$ & Aggregate & & & & $\begin{array}{l}\text { Investigates how the ability to measure } \\
\text { metrics may influence firm } \\
\text { performance }\end{array}$ \\
\hline \begin{tabular}{|l|} 
Perkins and Rao \\
$(1990)$
\end{tabular} & Aggregate & $\sqrt{ }$ & & & $\begin{array}{l}\text { Examines the impact of managerial } \\
\text { experience on information use }\end{array}$ \\
\hline Sinkula (1994) & Aggregate & & & & $\begin{array}{l}\text { Develops conceptual model to uncover } \\
\text { how organizations process market } \\
\text { information }\end{array}$ \\
\hline $\begin{array}{l}\text { Sinkula et al. } \\
\text { (1997) }\end{array}$ & Aggregate & & & & $\begin{array}{l}\text { Investigates the impact of } \\
\text { organizational learning on } \\
\text { information generation and } \\
\text { dissemination }\end{array}$ \\
\hline $\begin{array}{l}\text { Venkatesan } \\
(2017)\end{array}$ & Individual & & & & $\begin{array}{l}\text { Develops conceptual framework } \\
\text { designed to guide firms to manage } \\
\text { customers by using four key metrics }\end{array}$ \\
\hline This Paper & Individual & $\sqrt{ }$ & $\sqrt{ }$ & $\sqrt{ }$ & $\begin{array}{l}\text { Examines how marketers make trade- } \\
\text { offs between metrics for different types } \\
\text { of decisions and tasks }\end{array}$ \\
\hline
\end{tabular}


Table 2. Data Collection Procedure and Example

\begin{tabular}{|c|c|c|c|c|c|}
\hline Step & Description & \multicolumn{4}{|c|}{ Example } \\
\hline \multirow[t]{7}{*}{1} & \multirow{7}{*}{$\begin{array}{l}\text { Select } 2 \text { of } 7 \text { marketing budgetary decisions } \\
\text { with which you have had experience (if } \\
\text { have experience with more than } 2 \text { decisions, } \\
\text { focus on the } 2 \text { decisions that you have the } \\
\text { most experience) }\end{array}$} & \multicolumn{4}{|c|}{ Consumer Promotions $\longrightarrow$} \\
\hline & & \multicolumn{4}{|c|}{ Digital Advertising } \\
\hline & & \multicolumn{4}{|c|}{ Distribution } \\
\hline & & \multicolumn{4}{|c|}{ New Product Development } \\
\hline & & \multicolumn{4}{|c|}{ Pricing } \\
\hline & & \multicolumn{4}{|c|}{ Trade Promotions } \\
\hline & & \multicolumn{4}{|c|}{ Traditional Advertising } \\
\hline \multirow[t]{14}{*}{2} & \multirow{14}{*}{$\begin{array}{l}\text { For Decision 1, indicate which of } 26 \text { metrics } \\
\text { you would like to include in your idealized } \\
\text { dashboard }\end{array}$} & \multicolumn{4}{|c|}{ Consumer Promotions Dashboard Metrics } \\
\hline & & \multicolumn{2}{|c|}{ Acquisition Cost } & \multicolumn{2}{|c|}{ Quality } \\
\hline & & \multicolumn{2}{|c|}{ Awareness } & \multicolumn{2}{|c|}{ Retention } \\
\hline & & \multicolumn{2}{|c|}{ Brand. Expend. } & \multicolumn{2}{|c|}{ ROI } \\
\hline & & \multicolumn{2}{|r|}{ CLV } & \multicolumn{2}{|c|}{ ROMI } \\
\hline & & \multicolumn{2}{|c|}{ Consideration } & \multicolumn{2}{|c|}{ ROS } \\
\hline & & \multicolumn{2}{|c|}{ EVA } & & ction \\
\hline & & $<\mathrm{L}$ & reability & Segl & Profit \\
\hline & & & oyalty & Shar & Voice \\
\hline & & $\angle M$ & ket Share & Shar & Wallet \\
\hline & & $\sum 1$ & t Profit & & \\
\hline & & Net & rom Score & Targ & olume \\
\hline & & & NPV & & s Q \\
\hline & & & eference & Total & tomers \\
\hline 3 & For Decision 1, rank-order the included & Rank & & Metric & \\
\hline & metrics for your dashboard when making & 1 & & Awarenes & \\
\hline & this decision internally by you and your & 2 & & Likeabilit & \\
\hline & marketing function & 3 & & ROI & \\
\hline & & 4 & & Share of $\mathrm{Vo}_{\mathrm{O}}$ & \\
\hline & & 5 & & Market Sha & \\
\hline & & 6 & & Net Profit & \\
\hline 4 & For Decision 1, rank-order the included & Rank & & Metric & \\
\hline & metrics for your dashboard when seeking & 1 & & ROI & \\
\hline & top management's approval & 2 & & Market Sha & \\
\hline & & 3 & & Awarenes & \\
\hline & & 4 & & Net Profit & \\
\hline & & 5 & & Likeability & \\
\hline & & 6 & & Share of $\mathrm{Vo}$ & \\
\hline 5 & $\begin{array}{l}\text { For Decision } 1, \text { rate the accuracy and } \\
\text { frequency of use for each metric included in } \\
\text { your dashboard }\end{array}$ & & Ietric & $\begin{array}{c}\text { How } \\
\text { Accurate? } \\
\text { (1-7 scale) }\end{array}$ & $\begin{array}{l}\text { How Often } \\
\text { Used? } \\
(1-7 \text { scale })\end{array}$ \\
\hline & & & areness & & \\
\hline & & & eability & & \\
\hline & & $\mathrm{Ma}$ & et Share & & \\
\hline & & & Profit & & \\
\hline & & & $\mathrm{ROI}$ & & \\
\hline & & Shat & of Voice & & \\
\hline 6 & Repeat steps 2-5 for Decision 2 & Repeat. & eps 2-5 for Tro & ditional Ad & ising Decision \\
\hline 7 & $\begin{array}{l}\text { Questions on manager, firm, marketing } \\
\text { function, industry, and perceptions of data } \\
\text { quality }\end{array}$ & & See Appendix & able 1 for $q$ & tions \\
\hline
\end{tabular}


Table 3. Detailed Information on Metrics per Type of Marketing Budget Decision

\begin{tabular}{|c|c|c|c|c|c|c|c|c|c|c|c|c|c|c|c|c|c|c|c|c|c|c|c|c|}
\hline \multirow{3}{*}{$\begin{array}{l}\text { Type of } \\
\text { Decision } \\
\text { Type of Task } \\
\text { Metric }\end{array}$} & \multicolumn{6}{|c|}{ Consumer Promotions } & \multicolumn{6}{|c|}{ Digital Advertising } & \multicolumn{6}{|c|}{ Distribution } & \multicolumn{6}{|c|}{ New Product Development } \\
\hline & \multicolumn{2}{|c|}{$B Y O$} & \multicolumn{2}{|c|}{ Internal } & \multicolumn{2}{|c|}{ External } & \multicolumn{2}{|c|}{$B Y O$} & \multicolumn{2}{|c|}{ Internal } & \multicolumn{2}{|c|}{ External } & \multicolumn{2}{|c|}{$B Y O$} & \multicolumn{2}{|c|}{ Internal } & \multicolumn{2}{|c|}{ External } & \multicolumn{2}{|c|}{$B Y O$} & \multicolumn{2}{|c|}{ Internal } & \multicolumn{2}{|c|}{ External } \\
\hline & $\%$ & Rank & Ave & Rank & Ave & Rank & $\%$ & Rank & Ave & Rank & Ave & Rank & $\%$ & Rank & Ave & Rank & Ave & Rank & $\%$ & Rank & Ave & Rank & Ave & Rank \\
\hline Acquisition Cost & 0.21 & 16 & 4.58 & 17 & 4.55 & 16 & 0.29 & 7 & 4.54 & 6 & 4.47 & 4 & 0.19 & 16 & 4.17 & 6 & 4.75 & 11 & 0.26 & 10 & 5.41 & 23 & 5.49 & 21 \\
\hline Awareness & 0.26 & 5 & 95 & 9 & 4.59 & 17 & 32 & 3 & 4.94 & 14 & 5.08 & 13 & 0.28 & 8 & 5.39 & 21 & .56 & 8 & 0.24 & 14 & 4.87 & 15 & 3 & 16 \\
\hline Branc & 22 & 15 & 7 & 21 & 5.06 & 22 & & 14 & & 12 & 4.93 & 11 & 0.22 & 13 & & 1 & 5.43 & 17 & 0.24 & 13 & 4.91 & 6 & & 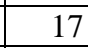 \\
\hline CLV & 23 & 10 & 3.89 & 8 & 3.86 & 8 & 18 & 19 & 5.63 & 21 & 5.80 & 23 & 0.22 & 13 & & 16 & 5.86 & 23 & .23 & 15 & & 11 & & . \\
\hline Consi & 16 & 21 & 4.96 & 20 & 5.48 & 25 & 14 & 23 & 6.50 & 26 & 6.28 & 25 & 0.11 & 21 & 50 & 22 & 5.29 & 16 & 0.15 & 23 & 4.79 & 13 & 4.96 & 18 \\
\hline EVA & 20 & 18 & 4.56 & & 4.75 & 19 & & 20 & 5.00 & 15 & 5.42 & 20 & 0.16 & 17 & & 19 & .60 & 20 & .22 & 16 & 3 & 24 & 8 & 25 \\
\hline & 24 & 8 & 4 & 2 1 & 4.13 & 11 & & 13 & 4.76 & 11 & 4.75 & 8 & 0.25 & 10 & & 15 & 4.56 & 9 & 0.30 & 8 & 4.2 & 7 & & 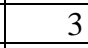 \\
\hline & 30 & 3 & 4. & & 4.42 & 13 & & 4 & 5.36 & 17 & 5.14 & 15 & 0.34 & 4 & & 17 & 5.59 & 19 & 0.35 & 4 & 7. & 8 & 2 & 13 \\
\hline & 23 & 10 & 5.00 & 22 & 4.46 & 15 & & 11 & 4.72 & 8 & 4.86 & 9 & 0.25 & 10 & & 3 & 3.63 & 3 & 0.30 & 9 & 5.09 & 18 & .72 & 14 \\
\hline & 26 & 5 & 3.66 & fot & 317 & 2 & & 9 & 4.13 & 3 & 4.62 & 6 & 0.45 & 1 & 2. & 1 & 2.97 & 1 & 0.42 & 1 & & 5 & 378 & - \\
\hline & & & & 4 & & 7 & & 24 & & 25 & 6.49 & 26 & 0.05 & 25 & & 26 & & 26 & & 25 & & 9 & & 12 \\
\hline $\mathrm{NP}$ & 15 & & 4 & at & 4.43 & 14 & & 5 & 4.73 & 9 & 5.27 & 18 & 0.23 & 12 & & 12 & 4.60 & 10 & 0.17 & 20 & 9 & 2 & 4 & 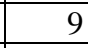 \\
\hline & 16 & 2 & 4.69 & & 4.85 & 20 & & & 6.00 & 22 & 6.03 & 24 & 0.27 & 9 & & \begin{tabular}{l|}
9 \\
\end{tabular} & 4.94 & 14 & 0.17 & 19 & It & 3 & 1 & 5 \\
\hline & 23 & 13 & 5.14 & 24 & 5.44 & 24 & 19 & 16 & 6.02 & 23 & 5.74 & 22 & 0.16 & 17 & 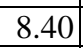 & 25 & 6.50 & 24 & 0.31 & 5 & 3.53 & 1 & 4.22 & 6 \\
\hline & & 4 & & 7 & 3.91 & 9 & & 12 & 5.11 & 16 & 4.8 & 10 & 0.22 & 13 & & 24 & 5.14 & 15 & & 18 & & 26 & & 22 \\
\hline & 3 & & & & & 5 & & 1 & 3 & 2 & 3.47 & 1 & & 4 & & 2 & 2 & 2 & 37 & 3 & 2 & 4 & 30 & 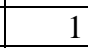 \\
\hline & 25 & 7 & 4.10 & & 3.67 & 4 & & 8 & 3.62 & 1 & 3.65 & 2 & 0.14 & 19 & & 8 & 4.89 & 13 & 0.31 & 5 & 5.40 & 21 & 8 & 11 \\
\hline & 20 & 191 & 3.39 & 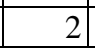 & 3.58 & 3 & & 9 & 4.45 & 4 & 4.16 & 3 & \begin{tabular}{l|l}
0.38 \\
\end{tabular} & 2 & & 5 & 3.63 & 3 & 0.26 & 10 & 5.10 & 19 & .47 & 10 \\
\hline Sat & 32 & 2 & 3.73 & 6 & 4.27 & 12 & 4 & 2 & 4.52 & 5 & 4.67 & 7 & 0.38 & 2 & 3.92 & 4 & 4.38 & 7 & 0.37 & 2 & 4.17 & 6 & 4.33 & -7 \\
\hline & 24 & 8 & 5.37 & & 5.13 & $8 \mathrm{c}$ & & 8 & 6.06 & & 5.23 & 17 & 0.13 & 20 & & 0 & 5.50 & 18 & 0.22 & 17 & 4.95 & 7 & 5.29 & 20 \\
\hline & & & & & & 20 & & 6 & & 10 & & 12 & & 23 & & 20 & & 22 & & 21 & & 4 & 65 & 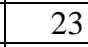 \\
\hline Sha & 0.21 & 16 & 5.00 & 22 & 4.73 & 18 & 0.16 & 20 & 5.60 & 20 & 5.53 & $21 \mid$ & 0.09 & 23 & 4.50 & \begin{tabular}{l|l|}
13 \\
\end{tabular} & 3.67 & 5 & 0.13 & 24 & 5.40 & 21 & 6.48 & 26 \\
\hline & 14 & 25 & 3.59 & 3 & 3.77 & 6 & 0.15 & 22 & 5.39 & 18 & 4.59 & 5 & 0.11 & 21 & 6.00 & 23 & 5.71 & 21 & 0.15 & 22 & 4.72 & 12 & 4.03 & 4 \\
\hline Target Volume & 0.23 & 13 & 4.47 & 13 & 4.97 & 21 & 0.31 & 5 & 5.41 & 19 & 5.38 & 19 & 0.31 & 6 & 4.20 & 7 & 3.70 & 6 & 0.31 & 5 & 4.50 & 10 & 4.33 & + \\
\hline Tobin's Q & 0.06 & 26 & 2.60 & 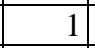 & 2.50 & 1 & 0.11 & 26 & 4.61 & 7 & 5.19 & 16 & 0.05 & 25 & 5.00 & 18 & 6.67 & 25 & 0.06 & 26 & 5.64 & 25 & 5.73 & 24 \\
\hline Total Customers & 0.39 & 1 & 4.64 & 18 & 4.13 & 10 & 0.29 & 6 & 4.93 & 13 & 5.14 & 14 & 0.30 & 7 & 4.79 & 14 & 4.79 & 12 & 0.26 & 10 & 5.24 & 20 & 5.18 & 19 \\
\hline
\end{tabular}


Table 3. Continued

\begin{tabular}{|c|c|c|c|c|c|c|c|c|c|c|c|c|c|c|c|c|c|c|c|c|c|c|c|c|}
\hline \multirow{3}{*}{$\begin{array}{l}\text { Type of } \\
\text { Decision } \\
\text { Type of Task } \\
\text { Metric }\end{array}$} & \multicolumn{6}{|c|}{ Pricing } & \multicolumn{6}{|c|}{ Traditional Advertising } & \multicolumn{6}{|c|}{ Trade Promotions } & \multicolumn{6}{|c|}{ Overall } \\
\hline & \multicolumn{2}{|c|}{$B Y O$} & \multicolumn{2}{|c|}{ Internal } & \multicolumn{2}{|c|}{ External } & \multicolumn{2}{|c|}{$B Y O$} & \multicolumn{2}{|c|}{ Internal } & \multicolumn{2}{|c|}{ External } & \multicolumn{2}{|c|}{$B Y O$} & \multicolumn{2}{|c|}{ Internal } & \multicolumn{2}{|c|}{ External } & \multicolumn{2}{|c|}{$B Y O$} & \multicolumn{2}{|c|}{ Internal } & \multicolumn{2}{|c|}{ External } \\
\hline & $\%$ & Rank & Ave & Rank & Ave & Rank & $\%$ & Rank & Ave & Rank & Ave & Rank & $\%$ & Rank & Ave & Rank & Ave & Rank & $\%$ & Rank & Ave & Rank & Ave & Rank \\
\hline Acquisition Cost & 0.29 & 5 & 3.59 & 3 & 3.82 & 3 & 0.20 & 14 & 4.93 & 19 & 3.98 & 5 & 0.16 & 20 & 5.13 & 21 & 4.56 & 20 & 0.24 & 13 & 4.65 & 12 & 4.52 & -1 \\
\hline Awareness & .19 & 14 & 80 & 15 & .52 & 25 & 26 & 11 & .94 & 20 & 4.58 & 13 & 0.22 & 6 & .55 & 5 & 3.95 & 12 & 0.26 & 10 & 4.70 & 14 & .80 & 14 \\
\hline Brand & 7 & 19 & & 24 & 5.09 & 19 & 0.18 & 18 & & 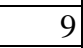 & 4.64 & 14 & 0.23 & 3 & & 13 & 3.91 & 11 & 0.22 & 15 & 4.79 & 17 & .85 & 17 \\
\hline CLV & 24 & 11 & 5.03 & 20 & 5.25 & 21 & 17 & 19 & 5.09 & 22 & 4.69 & 16 & 0.17 & 17 & 3.35 & 4 & 4.47 & 17 & 0.21 & 16 & 4.76 & 16 & 4.94 & 19 \\
\hline Consi & 10 & 25 & 4.62 & 13 & 5.38 & 23 & 0.13 & 22 & 5.19 & 25 & 5.00 & 21 & 0.12 & 25 & 5.67 & 25 & 5.17 & 24 & 0.13 & 24 & 5.44 & 26 & 5.47 & 26 \\
\hline EVA & 9 & 13 & 4.19 & 8 & 4.54 & 14 & 0.19 & 15 & 4.92 & 18 & 4.92 & 20 & 0.22 & 6 & 3.86 & 9 & 3.73 & 6 & 19 & 18 & 4.83 & 18 & .05 & 22 \\
\hline Lik & t & 8 & 5.14 & 22 & 4.94 & 17 & 29 & 6 & 22 & 6 & 3.91 & 3 & 0.21 & 12 & 4.33 & 15 & 3.81 & 7 & 0.26 & 8 & 4.56 & 8 & 4.30 & 5 \\
\hline Loy & & 14 & 4.96 & 18 & 5.36 & 22 & 32 & 3 & 2 & 4 & 4.70 & 17 & 0.22 & 6 & 4.64 & 19 & 4.50 & 18 & 0 & 4 & 4.60 & 11 & 87 & 18 \\
\hline & & 10 & 4.36 & 11 & 3.97 & 7 & 30 & 5 & 4.30 & 8 & 4.57 & 12 & 0.14 & 23 & 2.79 & 2 & 2.86 & 1 & 0.26 & 10 & 4.56 & 7 & 4.46 & -1 \\
\hline Net I & 4 & 1 & 2.76 & 1 & 2.65 & 1 & 0.32 & 3 & 3.80 & 2 & 3.97 & 4 & 0.17 & 17 & 5.47 & 24 & 4.94 & 22 & 0.32 & 3 & 3.78 & 2 & 3.74 & 2 \\
\hline & & & & 21 & & 8 & & & & 26 & 2 & 25 & & 6 & & 8 & & 4 & & 5 & 20 & 25 & 28 & 4 \\
\hline $\mathrm{NP}$ & & & 5.41 & 23 & 4.47 & 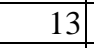 & 13 & 22 & 4.96 & 21 & 4.12 & 6 & 0.12 & 25 & 5.17 & 22 & 4.25 & 15 & 0.14 & 23 & 4.56 & 9 & 4.56 & 10 \\
\hline & & 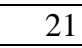 & 4.94 & 16 & 5.12 & 20 & 0.18 & 16 & 4.43 & 11 & 4.22 & 8 & 0.21 & 12 & 4.86 & 20 & 4.38 & 16 & 0.19 & 19 & 4.86 & 19 & 4.97 & 20 \\
\hline $\mathrm{Qu}$ & 20 & 12 & 3.74 & 4 & 3.89 & 4 & 0.25 & \begin{tabular}{l|l}
12 \\
\end{tabular} & 3.90 & 3 & 4.18 & 7 & 0.29 & 1 & 4.18 & 14 & 3.89 & 8 & \begin{tabular}{l|l|}
0.24 \\
\end{tabular} & 14 & 4.59 & 10 & 4.70 & 11 \\
\hline & & 7 & 4.94 & \begin{tabular}{l|}
17 \\
\end{tabular} & 4.42 & 12 & 0.27 & 10 & 4.49 & 13 & 4.78 & 18 & & 21 & 6.07 & 26 & 6.00 & 26 & 0.2 & 12 & 4.95 & 22 & 4.80 & 15 \\
\hline & & 3 & 3.43 & 2 & 3.61 & 2 & 1 & 1 & 3.50 & 3 & 3.40 & 1 & 22 & 6 & & 2 & 3.91 & 9 & 33 & 2 & 3.73 & 1 & 3.48 & - \\
\hline & & 16 & 5.58 & 25 & 4.17 & 8 & 0.29 & 6 & 4.41 & 10 & 4.26 & 9 & 0.28 & 2 & 2.59 & 1 & 3.15 & 2 & 0.26 & 9 & 4.28 & 4 & 4.02 & 4 \\
\hline & & 6 & 3.92 & 6 & 3.95 & 6 & 0.29 & 6 & 4.47 & 12 & 3.81 & 2 & 0.22 & 6 & 3.95 & 11 & 3.55 & 3 & 0.27 & 7 & 4.32 & 5 & 3.97 & 3 \\
\hline Satis & 37 & 2 & 4.29 & 10 & 4.33 & 10 & 0.36 & 2 & 4.29 & 7 & 4.49 & 10 & 0.23 & 3 & 3.78 & 7 & 3.70 & 5 & \begin{tabular}{l|l|}
0.34 \\
\end{tabular} & 1 & 4.19 & 3 & 4.40 & 6 \\
\hline & & & 4.54 & 12 & 4.21 & 9 & 0.15 & & 4.58 & 14 & 5.58 & 26 & 0.22 & 6 & 3.82 & 8 & 3.91 & 9 & 0.19 & 17 & 5.06 & 24 & 5.04 & 21 \\
\hline & & 25 & 6.71 & 26 & 5.50 & & & 24 & & 23 & 4.68 & 15 & & 17 & & 3 & 4.18 & 14 & & 22 & 4.97 & 23 & 5.18 & 23 \\
\hline Shar & 0.16 & 20 & 5.00 & 19 & 6.14 & 26 & 0.12 & 24 & 4.12 & 5 & 5.00 & 21 & 0.20 & 14 & 3.95 & 10 & 4.50 & 18 & 0.15 & 20 & 4.94 & 20 & 5.33 & 25 \\
\hline & 0.18 & 16 & 4.79 & 14 & 4.58 & 15 & 0.18 & 16 & 5.19 & 24 & 4.84 & 19 & 0.14 & 23 & 5.36 & 23 & 5.14 & 23 & 0.15 & 20 & 4.95 & 21 & 4.53 & \\
\hline Target Volume & 0.26 & 8 & 3.94 & 7 & 3.94 & 5 & 0.24 & 13 & 4.69 & 16 & 4.52 & 11 & 0.23 & 3 & 4.52 & 17 & 5.48 & 25 & 0.27 & 6 & 4.70 & 13 & 4.73 & 12 \\
\hline Tobin's Q & 0.07 & 26 & 3.90 & 5 & 4.40 & 11 & 0.09 & 26 & 4.89 & 17 & 5.17 & 23 & 0.15 & 21 & 4.40 & 16 & 4.07 & 13 & 0.09 & 26 & 4.48 & 6 & 4.77 & 13 \\
\hline Total Customers & 0.30 & 4 & 4.28 & \begin{tabular}{l|l}
9 \\
\end{tabular} & 4.93 & 16 & 0.28 & \begin{tabular}{l|l}
9 \\
\end{tabular} & 4.67 & 15 & 5.25 & 24 & 0.19 & 15 & 3.63 & 6 & 3.58 & $4]$ & 0.29 & 5 & 4.71 & 15 & 4.84 & 16 \\
\hline
\end{tabular}


Table 4. Main Effects for Metric and Decision and their Two Way Interactions

\begin{tabular}{|c|c|c|c|c|c|c|c|c|}
\hline & $\begin{array}{l}\text { Main Effect } \\
\text { Metric }\end{array}$ & $\begin{array}{l}\text { Traditional } \\
\text { Ad }\end{array}$ & Digital Ad & $\begin{array}{l}\text { Consumer } \\
\text { Promo }\end{array}$ & $\begin{array}{l}\text { Trade } \\
\text { Promo }\end{array}$ & Pricing & NPD & Distribution \\
\hline Main Effect Decision & 0.000 & 0.015 & -0.005 & 0.021 & 0.036 & -0.019 & 0.010 & -0.059 \\
\hline Tobin's Q & -1.238 & 0.140 & 0.104 & -0.173 & 0.307 & -0.057 & -0.148 & -0.173 \\
\hline Consideration & -0.642 & 0.037 & -0.006 & 0.102 & -0.056 & -0.149 & 0.085 & -0.013 \\
\hline Net Promo Score & -0.518 & 0.226 & -0.035 & 0.233 & 0.281 & -0.004 & -0.076 & -0.625 \\
\hline NPV & -0.510 & -0.116 & -0.148 & -0.001 & -0.107 & -0.142 & 0.090 & 0.424 \\
\hline Preference & -0.462 & -0.013 & -0.044 & -0.122 & 0.033 & -0.183 & -0.013 & 0.343 \\
\hline Stocks & -0.449 & 0.061 & -0.064 & -0.001 & -0.106 & 0.188 & 0.024 & -0.102 \\
\hline Share of Voice & -0.411 & -0.032 & 0.197 & -0.056 & 0.313 & -0.206 & 0.005 & -0.222 \\
\hline Share of Wallet & -0.374 & -0.110 & 0.002 & 0.171 & 0.148 & 0.055 & -0.212 & -0.054 \\
\hline CLV & -0.028 & -0.124 & -0.139 & 0.195 & -0.110 & 0.120 & 0.032 & 0.027 \\
\hline EVA & 0.023 & -0.002 & -0.151 & -0.036 & 0.124 & 0.192 & -0.035 & -0.093 \\
\hline Segment Profit & 0.024 & -0.145 & -0.022 & 0.086 & 0.171 & 0.073 & 0.023 & -0.186 \\
\hline Quality & 0.096 & 0.094 & -0.193 & -0.043 & 0.200 & 0.106 & 0.190 & -0.354 \\
\hline Branding Expend & 0.114 & -0.103 & 0.086 & -0.004 & 0.117 & -0.118 & 0.006 & 0.016 \\
\hline Likeability & 0.121 & 0.076 & -0.051 & -0.059 & -0.123 & -0.015 & 0.076 & 0.096 \\
\hline Acquisition Cost & 0.141 & -0.105 & 0.122 & -0.074 & -0.143 & 0.218 & 0.026 & -0.044 \\
\hline Awareness & 0.189 & -0.040 & 0.106 & 0.063 & 0.027 & -0.191 & -0.051 & 0.088 \\
\hline ROMI & 0.229 & 0.035 & 0.209 & 0.053 & 0.245 & -0.197 & -0.016 & -0.329 \\
\hline Retention & 0.235 & 0.029 & 0.080 & 0.189 & -0.162 & 0.101 & -0.132 & -0.104 \\
\hline ROI & 0.272 & 0.150 & 0.056 & -0.194 & -0.160 & 0.005 & 0.069 & 0.074 \\
\hline Loyalty & 0.340 & 0.065 & -0.011 & 0.032 & -0.063 & -0.194 & 0.040 & 0.130 \\
\hline Market Share & 0.347 & 0.091 & 0.017 & -0.120 & -0.153 & 0.054 & -0.023 & 0.134 \\
\hline Net Profit & 0.404 & -0.058 & -0.098 & -0.117 & -0.453 & 0.239 & 0.166 & 0.321 \\
\hline Target Volume & 0.455 & -0.101 & -0.013 & -0.122 & -0.122 & 0.045 & 0.059 & 0.253 \\
\hline ROS & 0.491 & -0.007 & 0.004 & -0.125 & -0.025 & 0.036 & -0.140 & 0.256 \\
\hline Total Customers & 0.515 & -0.060 & -0.001 & 0.181 & -0.072 & -0.010 & -0.084 & 0.046 \\
\hline Satisfaction & 0.639 & 0.013 & -0.008 & -0.058 & -0.109 & 0.033 & 0.039 & 0.090 \\
\hline
\end{tabular}

The grand mean is -0.00002 in the cell of the first row and column. The main effects for metrics is in the first column; the main effects for decisions are in the first row; and the interactions are in rows 2 to 27 and columns 2 to 8 . Coefficients that are significant a level 0.05 are in red italics. 
Table 5. Covariates in Latent Utilities

\begin{tabular}{|c|c|c|c|c|c|c|c|c|c|c|c|c|c|c|c|c|c|c|c|c|c|}
\hline \multirow{3}{*}{\begin{tabular}{|l|} 
Category \\
Variable \\
Metric
\end{tabular}} & \multirow{2}{*}{\multicolumn{3}{|c|}{$\begin{array}{l}\text { Data Quality } \\
\text { Importance of } \\
\text { Measurement }\end{array}$}} & \multicolumn{6}{|c|}{ Recent Performance } & \multicolumn{6}{|c|}{ Managerial Characteristics } & \multicolumn{6}{|c|}{ Marketing Characteristics } \\
\hline & & & & \multicolumn{3}{|c|}{$\begin{array}{c}\text { Recent Business } \\
\text { Performance } \\
\end{array}$} & \multicolumn{3}{|c|}{$\begin{array}{c}\text { Recent Marketing } \\
\text { Performance }\end{array}$} & \multicolumn{3}{|c|}{ Work Experience } & \multicolumn{3}{|c|}{$\begin{array}{l}\text { Top Marketing } \\
\text { Manager }\end{array}$} & \multicolumn{3}{|c|}{$\begin{array}{l}\text { Firm's Market } \\
\text { Orientation } \\
\end{array}$} & \multicolumn{3}{|c|}{$\begin{array}{c}\text { Importance of } \\
\text { Marketing }\end{array}$} \\
\hline & BYO & $\begin{array}{l}\text { Int- } \\
\text { ernal }\end{array}$ & $\begin{array}{l}\text { Ext- } \\
\text { ernal }\end{array}$ & $\mathrm{BYO}$ & $\begin{array}{l}\text { Int- } \\
\text { ernal }\end{array}$ & $\begin{array}{l}\text { Ext- } \\
\text { ernal }\end{array}$ & BYO & $\begin{array}{l}\text { Int- } \\
\text { ernal }\end{array}$ & \begin{tabular}{|l|} 
Ext- \\
ernal
\end{tabular} & BYO & $\begin{array}{l}\text { Int- } \\
\text { ernal }\end{array}$ & \begin{tabular}{l|} 
Ext- \\
ernal
\end{tabular} & $\mathrm{BYO}$ & $\begin{array}{l}\text { Int- } \\
\text { ernal }\end{array}$ & $\begin{array}{l}\text { Ext- } \\
\text { ernal }\end{array}$ & BYO & $\begin{array}{l}\text { Int- } \\
\text { ernal }\end{array}$ & $\begin{array}{l}\text { Ext- } \\
\text { ernal }\end{array}$ & BYO & \begin{tabular}{l|} 
Int- \\
ernal
\end{tabular} & $\begin{array}{l}\text { Ext- } \\
\text { ernal }\end{array}$ \\
\hline Net Profit & .08 & .00 & -.02 & .03 & .08 & .15 & .01 & -.06 & -.07 & .11 & .14 & .24 & -.21 & -.30 & -.40 & .04 & .01 & .05 & -.15 & -.24 & -.24 \\
\hline ROI & .20 & .20 & .38 & .00 & -.08 & -.01 & -.12 & -.36 & -.28 & .02 & -.06 & -.10 & -.24 & -.31 & -.45 & .04 & .16 & -.02 & -.16 & -.18 & -.28 \\
\hline ROS & .33 & .41 & .42 & -.08 & -.14 & -.15 & -.04 & -.09 & -.05 & .12 & .11 & .11 & -.19 & -.12 & -.20 & .07 & .07 & .07 & -.05 & -.06 & -.14 \\
\hline ROMI & .16 & .21 & .17 & -.04 & -.10 & -.11 & .08 & .00 & .08 & .18 & .22 & .20 & -.23 & -.08 & -.21 & -.01 & -.01 & -.06 & -.11 & -.10 & -.11 \\
\hline NPV & .19 & .11 & .17 & .02 & -.05 & -.01 & -.20 & -.53 & -.64 & .04 & -.01 & -.01 & -.09 & -.01 & .14 & .15 & .44 & .40 & .00 & .09 & .13 \\
\hline EVA & .15 & -.12 & -.05 & -.11 & -.10 & -.22 & .07 & .21 & .24 & -.06 & -.25 & -.27 & -.13 & -.15 & -.10 & .23 & .35 & .41 & -.04 & .00 & -.02 \\
\hline Brandi & .22 & .33 & .29 & -.13 & -.20 & -.24 & .13 & .17 & .24 & .09 & .09 & .10 & -.23 & -.22 & -.39 & .04 & .03 & .00 & -.11 & -.12 & -.15 \\
\hline Stocks & .01 & -.19 & -.23 & .06 & .18 & .15 & .07 & .04 & .08 & .06 & -.06 & -.04 & .07 & .39 & .35 & -.15 & -.40 & -.32 & .14 & .47 & .45 \\
\hline Tobin's Q & -.42 & -1.17 & -1.18 & .36 & .71 & .73 & -.04 & -.13 & -.13 & -.19 & -.45 & -.54 & .31 & .59 & .57 & -.11 & -.25 & -.09 & .28 & .75 & .70 \\
\hline Target Volu & .09 & -.04 & -.09 & .00 & .03 & .03 & .11 & .14 & .12 & .04 & -.02 & -.04 & -.35 & -.36 & -.29 & -.03 & -.08 & -.02 & .05 & .12 & .08 \\
\hline Acquisition Cost & .09 & -.07 & -.05 & .01 & .01 & .10 & .08 & .04 & .08 & .02 & -.05 & \begin{tabular}{l|l}
-.09 \\
\end{tabular} & -.22 & -.33 & -.23 & .00 & .00 & -.04 & -.14 & -.17 & -.20 \\
\hline Segmen & .26 & .19 & .17 & -.09 & -.11 & -.06 & .15 & .25 & .10 & .05 & .07 & .02 & -.20 & -.14 & -.17 & -.09 & -.25 & -.18 & -.04 & .03 & .04 \\
\hline CLV & .17 & .05 & .04 & -.13 & -.14 & -.23 & .08 & .06 & .00 & .10 & .10 & .11 & -.07 & .16 & .18 & .08 & .08 & .13 & .00 & .12 & .11 \\
\hline Market Share & .11 & -.03 & -.03 & -.04 & -.06 & .03 & .12 & .20 & .18 & .06 & .03 & .04 & -.07 & .09 & .09 & -.09 & -.15 & -.25 & .00 & .12 & .10 \\
\hline Awareness & .10 & -.09 & -.07 & .04 & .14 & .17 & .02 & -.06 & -.08 & .07 & -.01 & -.06 & -.11 & -.07 & .15 & .08 & .10 & .06 & -.18 & -.23 & -.18 \\
\hline Satisfaction & .15 & .09 & .04 & -.08 & -.02 & -.04 & .07 & .11 & .04 & .03 & .02 & .05 & -.19 & -.13 & -.12 & .15 & .07 & .11 & -.14 & -.07 & -.03 \\
\hline Likeability & -.09 & -.24 & -.26 & -.04 & .05 & .01 & .00 & -.11 & -.07 & .01 & -.09 & -.06 & -.08 & .12 & .22 & .12 & .15 & .12 & .12 & .25 & .29 \\
\hline Preference & -.10 & -.37 & -.41 & -.13 & -.17 & -.16 & .00 & .02 & .02 & -.09 & -.26 & -.25 & .23 & .63 & .63 & .21 & .26 & .26 & -.03 & -.01 & 03 \\
\hline Net Promos & .04 & -.20 & -.15 & .08 & .22 & .21 & .04 & .00 & -.08 & .02 & -.09 & -.08 & -.11 & -.27 & -.10 & -.10 & -.35 & -.24 & .09 & .32 & .27 \\
\hline Loyalty & .10 & -.03 & -.08 & -.08 & -.11 & -.08 & .03 & .05 & .05 & .03 & -.05 & -.01 & -.02 & .25 & .13 & .06 & .01 & .00 & .00 & .06 & .12 \\
\hline Quality & .25 & .38 & .30 & -.11 & -.08 & -.14 & -.07 & -.17 & -.17 & .04 & .08 & .07 & -.24 & -.26 & -.26 & .18 & .19 & .23 & -.06 & -.07 & .04 \\
\hline Consideration & .09 & -.08 & -.14 & .08 & .17 & .26 & .06 & .11 & -.13 & .02 & -.16 & -.11 & .07 & .45 & .50 & -.12 & -.31 & -.24 & .08 & .30 & .35 \\
\hline Total Customers & .05 & -.04 & -.02 & -.09 & -.07 & -.14 & .11 & .04 & .06 & .10 & .10 & .05 & -.28 & -.26 & -.27 & .03 & .08 & .08 & -.18 & -.22 & -.20 \\
\hline Retention & .18 & .05 & .04 & -.08 & -.08 & -.14 & -.03 & -.12 & -.07 & .13 & .18 & .17 & -.12 & -.14 & -.03 & -.05 & -.08 & -.09 & -.08 & .00 & -.01 \\
\hline Share of Wallet & .15 & .00 & .08 & .14 & .26 & .20 & .02 & .03 & -.10 & .13 & .17 & .14 & .10 & .47 & .35 & -.06 & -.18 & -.01 & .06 & .29 & .28 \\
\hline Share of Voice & .01 & -.12 & -.16 & -.03 & .10 & .00 & .20 & .35 & .48 & .01 & -.07 & -.03 & -.21 & -.11 & -.06 & -.05 & -.27 & -.23 & -.03 & .01 & .00 \\
\hline
\end{tabular}

Significant coefficients at level 0.05 are in red italics. 
Table 5. Continued

\begin{tabular}{|c|c|c|c|c|c|c|c|c|c|c|c|c|c|c|c|c|c|c|c|c|c|}
\hline \multirow{3}{*}{$\begin{array}{l}\text { Category } \\
\text { Variable } \\
\text { Metric } \\
\end{array}$} & \multirow{2}{*}{\multicolumn{3}{|c|}{$\begin{array}{c}\text { Marketing } \\
\text { Characteristics } \\
\text { Marketing } \\
\text { Responsibilities }\end{array}$}} & \multicolumn{12}{|c|}{ Firm Characteristics } & \multicolumn{6}{|c|}{ Industry Characteristics } \\
\hline & & & & \multicolumn{3}{|c|}{ Small Firm } & \multicolumn{3}{|c|}{ Large Firm } & \multicolumn{3}{|c|}{$\mathrm{B} 2 \mathrm{~B}$ versus $\mathrm{B} 2 \mathrm{C}$} & \multicolumn{3}{|c|}{$\begin{array}{l}\text { Goods versus } \\
\text { Services }\end{array}$} & \multicolumn{3}{|c|}{$\begin{array}{c}\text { Market } \\
\text { Concentration }\end{array}$} & \multicolumn{3}{|c|}{ Life Cycle } \\
\hline & BYO & $\begin{array}{l}\text { Int- } \\
\text { ernal }\end{array}$ & $\begin{array}{l}\text { Ext- } \\
\text { ernal }\end{array}$ & BYO & \begin{tabular}{|l|} 
Int- \\
ernal
\end{tabular} & \begin{tabular}{|l|} 
Ext- \\
ernal
\end{tabular} & BYO & $\begin{array}{l}\text { Int- } \\
\text { ernal }\end{array}$ & $\begin{array}{l}\text { Ext- } \\
\text { ernal }\end{array}$ & BYO & $\begin{array}{l}\text { Int- } \\
\text { ernal }\end{array}$ & $\begin{array}{l}\text { Ext- } \\
\text { ernal }\end{array}$ & BYO & \begin{tabular}{|l|} 
Int- \\
ernal
\end{tabular} & $\begin{array}{l}\text { Ext- } \\
\text { ernal }\end{array}$ & BYO & \begin{tabular}{|l|} 
Int- \\
ernal
\end{tabular} & $\begin{array}{l}\text { Ext- } \\
\text { ernal }\end{array}$ & BYO & $\begin{array}{l}\text { Int- } \\
\text { ernal }\end{array}$ & $\begin{array}{l}\text { Ext- } \\
\text { ernal }\end{array}$ \\
\hline Net Profit & -.01 & -.07 & -.13 & .11 & .17 & .32 & .05 & -.01 & .02 & .01 & -.01 & .03 & -.05 & -.12 & -.08 & -.02 & -.11 & -.20 & -.04 & -.15 & -.23 \\
\hline $\mathrm{ROI}$ & .02 & -.02 & -.01 & .32 & .61 & .69 & .37 & .71 & .69 & -.06 & -.11 & -.15 & -.01 & .00 & .09 & .02 & -.13 & -.01 & -.04 & -.11 & -.07 \\
\hline ROS & .06 & .02 & .06 & -.06 & -.07 & -.07 & -.24 & -.56 & -.42 & .05 & .06 & .07 & -.10 & -.12 & -.12 & .13 & .16 & .15 & -.13 & -.22 & -.27 \\
\hline ROMI & .13 & .15 & .14 & -.02 & -.18 & -.05 & .15 & .10 & .12 & .02 & .06 & .00 & -.04 & -.10 & -.05 & .00 & -.05 & -.03 & .01 & -.03 & -.09 \\
\hline NPV & .05 & .05 & .09 & -.23 & -.43 & -.47 & .02 & -.10 & -.17 & -.03 & -.11 & -.13 & -.09 & -.19 & -.17 & .14 & .18 & .20 & .12 & .21 & .23 \\
\hline EVA & .05 & -.02 & -.02 & -.21 & -.24 & -.38 & -.11 & -.28 & -.23 & -.07 & -.21 & -.18 & .00 & .07 & .01 & .18 & .19 & .13 & .03 & .16 & .09 \\
\hline Brand & .07 & .05 & .05 & .08 & .01 & .03 & .12 & .06 & -.09 & -.02 & .00 & .01 & -.05 & -.01 & -.04 & -.04 & -.17 & -.09 & -.18 & -.29 & -.34 \\
\hline Stocks & .01 & -.02 & -.01 & -.21 & -.53 & -.53 & -.07 & -.24 & -.29 & .03 & .13 & .13 & .05 & .17 & .12 & .04 & .02 & -.04 & -.14 & -.32 & -.36 \\
\hline Tobir & -.05 & -.17 & -.22 & -.39 & -.86 & -.95 & .00 & -.43 & -.37 & -.15 & -.17 & -.21 & -.07 & -.14 & -.16 & .15 & .11 & .20 & .34 & .75 & .65 \\
\hline Targe & .07 & .06 & .08 & .26 & .30 & .15 & -.04 & -.29 & -.31 & .07 & .13 & .11 & -.03 & .03 & .00 & .20 & .27 & .22 & -.04 & .02 & -.03 \\
\hline Acquisition Cos & .13 & .11 & .14 & .15 & .08 & .17 & .21 & .23 & .21 & .08 & .08 & .19 & -.03 & -.11 & -.07 & -.18 & -.43 & -.45 & .07 & .26 & .31 \\
\hline Segm & .07 & .07 & .05 & -.23 & -.59 & -.58 & .03 & -.23 & -.20 & .01 & -.10 & -.11 & .06 & .12 & .10 & .13 & .08 & .20 & .00 & .02 & .07 \\
\hline CLV & .06 & .11 & .14 & -.02 & -.11 & -.23 & .04 & -.03 & -.07 & -.03 & -.12 & -.13 & -.05 & -.08 & -.10 & .13 & .05 & .08 & .01 & .07 & .04 \\
\hline Market & .04 & -.05 & -.01 & .04 & -.02 & .05 & .11 & .11 & .14 & -.03 & .00 & .00 & -.12 & -.18 & -.20 & .01 & -.06 & -.01 & -.11 & -.21 & -.25 \\
\hline Awar & -.02 & -.07 & -.05 & .00 & .00 & -.02 & .09 & -.01 & .09 & .01 & 03 & -.02 & -.04 & .01 & .00 & .02 & .13 & .07 & .05 & .06 & .20 \\
\hline Satisf & .03 & -.01 & -.04 & .25 & .26 & .28 & .00 & -.18 & -.13 & .08 & .11 & .12 & .03 & .13 & .05 & .05 & -.05 & -.02 & -.13 & -.24 & -.15 \\
\hline Likeability & -.01 & -.08 & -.11 & .00 & -.02 & -.05 & .09 & .05 & .15 & -.04 & -.02 & -.06 & .00 & -.01 & .03 & .11 & .13 & .14 & .00 & -.11 & -.12 \\
\hline Prefere & .10 & .10 & .06 & .03 & .09 & .14 & .15 & .15 & .21 & -.04 & -.02 & -.03 & -.04 & -.01 & .01 & .15 & .15 & .09 & -.05 & .02 & .04 \\
\hline Net Promo & -.04 & -.10 & -.10 & -.34 & -.71 & -.76 & .26 & .38 & .37 & -.09 & -.09 & -.07 & .07 & .24 & .18 & -.08 & -.23 & -.16 & .08 & -.04 & -.03 \\
\hline Loyalty & .07 & .02 & .04 & .13 & .12 & .19 & .21 & .28 & .24 & .12 & .21 & .14 & .02 & .11 & .08 & .07 & .01 & -.15 & -.10 & -.14 & -.14 \\
\hline Quality & .17 & .28 & .21 & .12 & .08 & .12 & -.03 & -.13 & -.05 & -.03 & -.07 & -.06 & -.05 & -.04 & -.01 & .33 & .47 & .34 & .02 & .00 & .11 \\
\hline Consider & -.01 & -.10 & -.06 & -.30 & -.60 & -.62 & -.11 & -.44 & -.43 & .00 & -.02 & .01 & -.01 & .07 & .05 & .26 & .29 & .40 & .07 & .08 & .10 \\
\hline Total Customers & .08 & .02 & .08 & .07 & .09 & -.01 & .01 & .02 & -.07 & .02 & .02 & .06 & -.03 & .02 & .01 & -.03 & -.11 & -.08 & -.05 & -.02 & -.10 \\
\hline Retention & -.04 & -.08 & -.13 & .06 & .10 & .15 & .04 & -.01 & -.03 & -.07 & -.08 & -.07 & .04 & .10 & .12 & .07 & .02 & .04 & -.05 & .01 & .03 \\
\hline Share of Wallet & -.07 & -.20 & -.24 & .13 & .18 & .01 & .18 & .22 & .12 & -.01 & .08 & .02 & -.06 & -.06 & -.13 & -.04 & -.27 & -.10 & -.09 & -.25 & -.29 \\
\hline Share of Voice & .11 & .07 & .02 & -.07 & -.28 & -.27 & .03 & .00 & -.04 & .07 & .16 & .18 & .00 & .03 & .08 & .10 & .09 & -.02 & -.12 & -.16 & -.07 \\
\hline
\end{tabular}

Significant coefficients at level 0.05 are in red italics. 


\section{Appendix Table 1. Variables, Operationalization, and Descriptive Statistics}

\begin{tabular}{|c|c|c|c|c|}
\hline $\begin{array}{l}\text { Variable } \\
\text { (source) }\end{array}$ & Operationalization & $\alpha$ & Mean & $\begin{array}{l}\text { St. } \\
\text { Dev. }\end{array}$ \\
\hline $\begin{array}{l}\text { Measurement } \\
\text { Importance } \\
\text { (Wang and } \\
\text { Strong 1996) }\end{array}$ & $\begin{array}{l}\text { Please rate the level of importance of the following for when you decide } \\
\text { the usefulness of a metric }(1=\text { not at all important; } 7=\text { extremely } \\
\text { important) } \\
\text { - Availability of the metric } \\
\text { - } \quad \text { Reliability of the metric } \\
-\quad \text { Accuracy of the metric } \\
-\quad \text { Effectiveness of the metric } \\
\text { - } \quad \text { Frequency metric is updated }\end{array}$ & .79 & 5.78 & .67 \\
\hline $\begin{array}{l}\text { Market } \\
\text { Orientation } \\
\text { (Deshpandé } \\
\text { and Farley } \\
\text { 1998; Kohli } \\
\text { and Jaworski } \\
1990 ; \\
\text { Verhoef and } \\
\text { Leeflang } \\
\text { 2009) }\end{array}$ & $\begin{array}{l}\text { How strongly do you agree or disagree with each of the following } \\
\text { statements ( } 1=\text { strongly disagree, } 7=\text { strongly agree) } \\
\text { - } \quad \text { Our business objectives are driven primarily by customer } \\
\text { satisfaction } \\
\text { - We constantly monitor our level of commitment and orientation to } \\
\text { - } \quad \text { Werving customer needs } \\
\text { - } \quad \text { Our successfrategn customer experiences throughout all business functions } \\
\text { - Wnderstanding of customer needs } \\
\text { - We measure customer satisfaction systematically and frequently } \\
\text { - We are more customer focused than our competitors } \\
\text { - I believe this business exists primarily to serve customers }\end{array}$ & .87 & 5.74 & .78 \\
\hline $\begin{array}{l}\text { Marketing } \\
\text { Importance } \\
\text { (Verhoef and } \\
\text { Leeflang } \\
\text { 2009) }\end{array}$ & $\begin{array}{l}\text { How strongly do you agree or disagree with each of the following } \\
\text { statements about top management in your firm ( } 1=\text { strongly disagree, } 7 \\
=\text { strongly agree) } \\
\text { - The functions performed by the marketing department are generally } \\
\text { considered to be more critical than other functions } \\
\text { - Marketing tends to dominate other functions in decision-making. }\end{array}$ & .63 & 5.30 & 1.14 \\
\hline $\begin{array}{l}\text { Work } \\
\text { Experience } \\
\text { (Mintz and } \\
\text { Currim 2013) }\end{array}$ & $\begin{array}{l}\text { Please indicate your level of work experience in the following } 3 \\
\text { questions }(1=<1 \text { year; } 2=1-5 \text { years; } 3=6-10 \text { years; } 4=11-20 \text { years; } 5 \\
=>20 \text { years) } \\
-\quad \text { How long have you been at your current position } \\
-\quad \text { How long have you been with your current employer? } \\
-\quad \text { How long have you been in your profession? }\end{array}$ & .87 & 2.99 & .84 \\
\hline $\begin{array}{l}\text { Top Level } \\
\text { Manager } \\
\text { (Mintz and } \\
\text { Currim 2013) }\end{array}$ & $\begin{array}{l}\text { Please indicate your job title }(0=\text { lower than VP-level [e.g., Director, } \\
\text { Manager]; } 1=\text { VP-level or higher [e.g., SVP, C-level or Owner] })\end{array}$ & --- & .63 & --- \\
\hline $\begin{array}{l}\text { Marketing } \\
\text { Responsibility }\end{array}$ & $\begin{array}{l}\text { Please indicate how involved you are in each of the areas }(1=\text { never } \\
\text { involved; } 7=\text { always involved }) \\
\text { - } \quad \text { Marketing budget } \\
\text { - } \quad \text { Financial reporting } \\
\text { - } \quad \text { Contact with customers } \\
\text { - } \quad \text { Contact with marketing vendors }\end{array}$ & .77 & 5.80 & .92 \\
\hline $\begin{array}{l}\text { Recent } \\
\text { Business } \\
\text { Performance }\end{array}$ & $\begin{array}{l}\text { Please indicate the level of performance of your firm relative to your } \\
\text { firm's stated objectives }(1=\text { much worse, } 7=\text { much better }) \\
\text { - How was the overall performance of your firm in the last } 3 \text { years? } \\
\text { - How was the overall performance of your firm relative to your } \\
\text { closest competitors in the last } 3 \text { years? }\end{array}$ & .72 & 5.71 & .93 \\
\hline
\end{tabular}




\begin{tabular}{|c|c|c|c|c|}
\hline $\begin{array}{l}\text { (Kohli and } \\
\text { Jaworski } \\
\text { 1990; Mintz } \\
\text { and Currim } \\
\text { 2013) }\end{array}$ & & & & \\
\hline $\begin{array}{l}\text { Marketing } \\
\text { Performance } \\
\text { (Mintz and } \\
\text { Currim 2013) }\end{array}$ & $\begin{array}{l}\text { Please indicate the level of performance of your overall marketing } \\
\text { relative to your firm's stated objectives }(1=\text { much worse, } 7=\text { much } \\
\text { better) } \\
\text { - How is your overall marketing performing this year? } \\
\text { - How is your overall marketing performing on financial measures } \\
\text { (i.e., profitability, sales, ROI, etc.) this year? } \\
\text { - How is your overall marketing performing on non-financial } \\
\text { measures (i.e., customer satisfaction, customer loyalty, market share, } \\
\text { etc.) this year? }\end{array}$ & .75 & 5.56 & .90 \\
\hline $\begin{array}{l}\text { Industry } \\
\text { Concentration } \\
\text { (Mintz and } \\
\text { Currim 2013) }\end{array}$ & $\begin{array}{l}\text { Approximately what percentage of sales does the largest } 4 \text { competing } \\
\text { businesses in your market control? }(0=0-50 \%, 1=51-100 \%)\end{array}$ & --- & .48 & --- \\
\hline $\begin{array}{l}\text { Product Life } \\
\text { Cycle } \\
\text { (Mintz and } \\
\text { Currim 2013) }\end{array}$ & $\begin{array}{l}\text { At which one of the following stages would you place your product? } \\
(0=\text { Introduction \& Growth; } 1 \text { = Mature \& Decline })\end{array}$ & --- & .40 & --- \\
\hline $\begin{array}{l}\text { B2B vs. B2C } \\
\text { (Verhoef and } \\
\text { Leeflang } \\
\text { 2009) }\end{array}$ & $\begin{array}{l}\text { Please indicate the extent to which your sales come from B2B or B2C } \\
\text { markets }(1=\text { mostly B2B, } 7=\text { mostly B2C })\end{array}$ & --- & 4.27 & 1.83 \\
\hline $\begin{array}{l}\text { Goods vs. } \\
\text { Services } \\
\text { (Verhoef and } \\
\text { Leeflang } \\
\text { 2009) }\end{array}$ & $\begin{array}{l}\text { Please indicate the extent to which your sales come from goods or } \\
\text { services markets }(1=\text { mostly goods, } 7=\text { mostly services })\end{array}$ & --- & 4.44 & 1.96 \\
\hline $\begin{array}{l}\text { Small-Size } \\
\text { Firm }\end{array}$ & Does your firm employ less than 250 employees? & --- & .25 & --- \\
\hline $\begin{array}{l}\text { Mid-Size } \\
\text { Firm }\end{array}$ & Does your firm employ between $250-990$ employees? & --- & .44 & --- \\
\hline $\begin{array}{l}\text { Large-Size } \\
\text { Firm }\end{array}$ & Does your firm employ more than 999 employees? & --- & .31 & --- \\
\hline
\end{tabular}


Appendix Table 2. Root Mean Square Error among the Estimated Intercepts and Scaled Effects for Different Identification Constraints in the Ordinal Probit Model

The scaled effects subtract the overall mean and divide by the error standard deviation. The RMSE for the scaled effects do not include the overall mean.

\begin{tabular}{cc|rc|rrr} 
Model A & $\begin{array}{c}\text { Fixed } \\
\text { Cut-points }\end{array}$ & Model B & $\begin{array}{c}\text { Fixed } \\
\text { Cut-points }\end{array}$ & $\begin{array}{r}\text { \% Reduction } \\
\text { in RMSE }\end{array}$ & $\begin{array}{r}\text { RMSE Raw } \\
\text { Intercepts }\end{array}$ & $\begin{array}{r}\text { RMSE } \\
\text { Scaled } \\
\text { Effects }\end{array}$ \\
\hline 1 & $-3 \& 3$ & 2 & $1 \& 10$ & 92.80 & 1.418 & 0.102 \\
1 & $-3 \& 3$ & 3 & $1 \& 100$ & 97.20 & 3.383 & 0.095 \\
1 & $-3 \& 3$ & 4 & $0 \& 1$ & 50.82 & 0.510 & 0.251 \\
2 & $1 \& 10$ & 3 & $1 \& 100$ & 92.71 & 2.513 & 0.183 \\
2 & $1 \& 10$ & 4 & $0 \& 1$ & 84.11 & 1.477 & 0.235 \\
3 & $1 \& 100$ & 4 & $0 \& 1$ & 90.87 & 3.232 & 0.295
\end{tabular}




\section{Appendix References}

Deshpandé, Rohit and John U. Farley (1998), "Measuring Market Orientation: Generalization and Synthesis," Journal of Market-Focused Management, 2 (3), 213-32.

Kohli, Ajay K. and Bernard J. Jaworski (1990), "Market Orientation: The Construct, Research Propositions, and Managerial Implications,” Journal of Marketing, 54 (2), 1-18.

Mintz, Ofer and Imran S. Currim (2013), "What Drives Managerial Use of Marketing and Financial Metrics and Does Metric Use Affect Performance of Marketing-Mix Activities?" Journal of Marketing, 77 (2), 17-40.

Verhoef, Peter C. and Peter S. H. Leeflang (2009), "Understanding the Marketing Department's Influence Within the Firm," Journal of Marketing, 73 (2), 14-37.

Wang, Richard Y. and Diane M. Strong (1996), "Beyond Accuracy: What Data Quality Means to Data Consumers," Journal of Management Information Systems, 12 (4), 5-33. 